TITLE:

\title{
Silver-loaded sodium titanate photocatalysts for selective reduction of carbon dioxide to carbon monoxide with water
}

\author{
$\operatorname{AUTHOR}(\mathrm{S}):$ \\ Zhu, Xing; Anzai, Akihiko; Yamamoto, Akira; \\ Yoshida, Hisao
}

\section{CITATION:}

Zhu, Xing ... [et al]. Silver-loaded sodium titanate photocatalysts for selective reduction of carbon dioxide to carbon monoxide with water. Applied Catalysis B: Environmental 2019, 243: 47-56

ISSUE DATE:

2019-04

URL:

http://hdl.handle.net/2433/234978

\section{RIGHT:}

(c) 2018. This manuscript version is made available under the CC-BY-NC-ND 4.0 license

http://creativecommons.org/licenses/by-nc-nd/4.0/; The full-text file will be made open to the public on 01 April 2021 in accordance with publisher's 'Terms and Conditions for Self-Archiving'; この論文は出版社版でありません。引用の際に は出版社版をご確認ご利用ください。; This is not the published version. Please cite only the published version. 


\title{
Silver-loaded sodium titanate photocatalysts for selective reduction of carbon dioxide to carbon monoxide with water
}

\author{
Xing Zhu, ${ }^{\text {a Akihiko Anzai, }}{ }^{\mathrm{a}}$ Akira Yamamoto, ${ }^{\mathrm{a}, \mathrm{b}}$ Hisao Yoshida ${ }^{\mathrm{a}, \mathrm{b}, *}$ \\ ${ }^{a}$ Graduate School of Human and Environmental Studies, Kyoto University, Kyoto 606-8501, Japan \\ ${ }^{b}$ Elements Strategy Initiative for Catalysts and Batteries (ESICB), Kyoto University, Kyoto 615-8520, Japan \\ *Corresponding author: yoshida.hisao.2a@kyoto-u.ac.jp
}

\begin{abstract}
To obtain more efficient photocatalyst for photocatalytic reduction of $\mathrm{CO}_{2}$ with $\mathrm{H}_{2} \mathrm{O}$ and figure out the reason for nonstoichiometric $\mathrm{O}_{2}$ evolution, silver-loaded sodium titanate photocatalysts were further studied in the improved reaction conditions. After preliminary tests for two kinds of sodium titanate samples with different ratio of sodium to titanium $\left(\mathrm{Na}_{2} \mathrm{Ti}_{6} \mathrm{O}_{13}\right.$ and $\left.\mathrm{Na}_{2} \mathrm{Ti}_{3} \mathrm{O}_{7}\right)$, several sodium hexatitanate $\left(\mathrm{Na}_{2} \mathrm{Ti}_{6} \mathrm{O}_{13}\right)$ photocatalysts were further prepared in the flux method by changing the parameters such as the flux, the loading amount of Ag cocatalyst, and the loading method of the Ag cocatalyst. As a result, a $\mathrm{Ag} / \mathrm{Na}_{2} \mathrm{Ti}_{6} \mathrm{O}_{13}$ sample prepared in a sodium chloride flux, with $1.0 \mathrm{wt} \%$ of Ag cocatalyst loaded by a photodeposition method, exhibited the highest production rate $\left(4.6 \mu \mathrm{mol} \mathrm{h}{ }^{-1}\right)$ and the highest selectivity (74\%) to carbon monoxide among the examined samples, which are more than 29 times higher production rate and 2.7 times higher selectivity to carbon monoxide than those in the previous report. Furthermore, although required oxygen production rate equivalent to the formation rates of the reduced products was not observed in the previous study, it was found that the developed $\mathrm{Ag} / \mathrm{Na}_{2} \mathrm{Ti}_{6} \mathrm{O}_{13}(\mathrm{NaCl})$ photocatalyst produced enough amount of oxygen after a long induction period of $50 \mathrm{~h}$ in the present condition. The reasons for the insufficient oxygen formation in the initial period were also investigated and clarified, i.e., the chloride residues and the photoadsorption of $\mathrm{O}_{2}$ on the surface are responsible for the insufficient $\mathrm{O}_{2}$ evolution at the initial period.
\end{abstract}

Keywords: Photocatalytic conversion of $\mathrm{CO}_{2}$; Carbon monoxide; Sodium titanate; Silver cocatalyst.

\section{Introduction}

Photocatalytic $\mathrm{CO}_{2}$ reduction with water using solar energy is the desirable method for not only decreasing $\mathrm{CO}_{2}$ emission, but also producing valuable chemicals that can be used directly as fuels or in further chemical syntheses [1-5]. Heterogeneous photocatalysis have been studied for the reduction of $\mathrm{CO}_{2}$ with water, and the products reported are formate, $\mathrm{CO}, \mathrm{CH}_{3} \mathrm{OH}$ and $\mathrm{CH}_{4}$ [6-14]. Among these possible reductive products from $\mathrm{CO}_{2}$, $\mathrm{CO}$ is the most useful product since it is a valuable chemical intermediate for further chemical syntheses and easily-separable from the aqueous reaction media to the gas phase. To obtain CO as a product, Ag cocatalyst was discovered [15], which has been widely studied in recent years, such as $\mathrm{Ag} / \mathrm{BaLa}_{4} \mathrm{Ti}_{4} \mathrm{O}_{15}$ [15], $\mathrm{Ag} / \mathrm{Ga}_{2} \mathrm{O}_{3}[16-20], \mathrm{Ag} / \mathrm{KCaSrTa}_{5} \mathrm{O}_{15}$ [21], $\mathrm{Ag} / \mathrm{La}_{2} \mathrm{Ti}_{2} \mathrm{O}_{7}$ [22], $\mathrm{Ag} / \mathrm{CaTiO}_{3}[23,24]$, and $\mathrm{Ag} / \mathrm{SrNb}_{2} \mathrm{O}_{6}[25,26]$. However, the photocatalytic activity has not been enough for the practical application. Thus, it is still imperative to develop highly efficient photocatalysts for this reaction.

In these reaction systems, it can be assumed that two reactions competitively occur, i.e., photocatalytic reduction of $\mathrm{CO}_{2}$ to form $\mathrm{CO}$ and $\mathrm{O}_{2}$ (Eq. 1) and photocatalytic water splitting into $\mathrm{H}_{2}$ and $\mathrm{O}_{2}$ (Eq. 2). In details, the reduction 
of $\mathrm{CO}_{2}$ and protons with the photoexcited electrons proceed to form $\mathrm{CO}$ and $\mathrm{H}_{2}$, respectively on the reductive sites of the photocatalyst surface (Eqs. 3 and 4), while the oxidation of water with positive holes into $\mathrm{O}_{2}$ and protons occurs on the oxidative sites (Eq. 5).

$$
\begin{aligned}
& \mathrm{CO}_{2} \rightarrow \mathrm{CO}+1 / 2 \mathrm{O}_{2} \\
& \mathrm{H}_{2} \mathrm{O} \rightarrow \mathrm{H}_{2}+1 / 2 \mathrm{O}_{2} \\
& \mathrm{CO}_{2}+2 \mathrm{H}^{+}+2 \mathrm{e}^{-} \rightarrow \mathrm{CO}+\mathrm{H}_{2} \mathrm{O} \\
& 2 \mathrm{H}^{+}+2 \mathrm{e}^{-} \rightarrow \mathrm{H}_{2} \\
& 2 \mathrm{H}_{2} \mathrm{O}+4 \mathrm{~h}^{+} \rightarrow \mathrm{O}_{2}+4 \mathrm{H}^{+}
\end{aligned}
$$

When no other reductive products than $\mathrm{CO}$ and $\mathrm{H}_{2}$ are observed in the reaction system, the selectivity toward $\mathrm{CO}$ evolution, $S_{\mathrm{CO}}(\%)$, and the ratio of the consumed electron and hole, $R\left(\mathrm{e}^{-} / \mathrm{h}^{+}\right)$, can be calculated according to Eqs. 6 and 7, respectively [24,26], where the production rate of $\mathrm{CO}, \mathrm{H}_{2}$ and $\mathrm{O}_{2}$ are referred to as $R_{\mathrm{CO}}, R_{\mathrm{H} 2}$ and $R_{\mathrm{O} 2}$, respectively. The value of $R\left(\mathrm{e}^{-} / \mathrm{h}^{+}\right)$should be unity if the two competitive reactions, Eqs. 1 and 2, take place ideally in any balance.

$$
\begin{aligned}
& S_{\mathrm{CO}}(\%)=100 \times R_{\mathrm{CO}} /\left(R_{\mathrm{CO}}+R_{\mathrm{H} 2}\right) \\
& R\left(\mathrm{e}^{-} / \mathrm{h}^{+}\right)=\left(2 R_{\mathrm{CO}}+2 R_{\mathrm{H} 2}\right) / 4 R_{\mathrm{O} 2}
\end{aligned}
$$

In our previous study [27], we focused on sodium hexatitanate $\left(\mathrm{Na}_{2} \mathrm{Ti}_{6} \mathrm{O}_{13}\right)$ since titanium and sodium are abundant elements in the Earth's crust. The sodium hexatitanate samples were prepared by a flux method, on which Ag cocatalyst was loaded. The Ag/ $/ \mathrm{Na}_{2} \mathrm{Ti}_{6} \mathrm{O}_{13}$ photocatalyst exhibited the photocatalytic activity for the $\mathrm{CO}_{2}$ reduction to CO. The photocatalyst consisted of unique rod-like fine crystal particles showing facets, and the Ag cocatalyst nanoparticles were deposited on the selected facets, especially after the photocatalytic reaction test. In this system, however, two problems remained; one was the low activity of $\mathrm{CO}$ evolution with low selectivity, such as $R_{\mathrm{CO}}=0.16$ $\mu \mathrm{mol} \mathrm{h}{ }^{-1}$ and $S_{\mathrm{CO}}=27 \%$, and the other was the uncertainty of the oxidation reaction, i.e., insufficient oxygen evolution, $R\left(\mathrm{e}^{-} / \mathrm{h}^{+}\right)<1$. As for the former problem, the reaction conditions should be reconsidered since we found recently that the reaction conditions, such as light intensity and $\mathrm{CO}_{2}$ concentration in the reaction mixture, much affect the production rates of carbon monoxide and oxygen [24]. As for the latter problem, so far, many photocatalytic systems have faced this problem, i.e., the ratio of the consumed electron and hole $R\left(\mathrm{e}^{-} / \mathrm{h}^{+}\right)$estimated from the production rates was not unity, which is not consistent to the stoichiometric ratio. Among the proposed explanations, the most convinced one would be that the difficulty of water oxidation is due to the high overpotential of $\mathrm{O}_{2}$ evolution, which originates from charge trapping by surface states and slow oxygen evolution kinetics [28-30]. This is also an explanation why some photocatalytic systems for water splitting produce $\mathrm{H}_{2}$ without sufficient amount of $\mathrm{O}_{2}$ (or $R_{\mathrm{H} 2} / R_{\mathrm{O}_{2}}>2$ ) [31]. In addition, photoadsorption of $\mathrm{O}_{2}$ on the photocatalyst surface [32,33] and the competitive oxidation of water to hydrogen peroxide $[34,35]$ are also possible in the photocatalytic reaction with water. What's more, for some special reaction systems using catalyst samples containing chloride residues originated from the catalyst preparation, such as a flux method with chloride flux, the residues of chloride may compete with oxygen evolution. Some researchers suggested that the $\mathrm{Cl}^{-}$that exists in the photocatalytic system can react with the photogenerated holes [36,37]. $\mathrm{Li}$ and co-workers claimed that the existence of $\mathrm{Cl}^{-}$affected both the $\mathrm{H}_{2}$ evolution and $\mathrm{O}_{2}$ evolution [38]. Furthermore, Iguchi et al. also reported that hypochlorous acid (HClO) was produced as an oxidation product of $\mathrm{Cl}^{-}$with the formation of reduction products such as $\mathrm{CO}$ and $\mathrm{H}_{2}$ under photoirradiation [39]. 
Thus, in the present study, the silver-loaded sodium titanate photocatalysts, one of which was once reported in the previous study [27], were again examined in the improved reaction conditions for the photocatalytic reduction of carbon dioxide by water. Two points were claimed in this study. First, after testing the composition of sodium titanate ( $\mathrm{Na}_{2} \mathrm{Ti}_{6} \mathrm{O}_{13}$ and $\mathrm{Na}_{2} \mathrm{Ti}_{3} \mathrm{O}_{7}$ ), the performance of the prepared $\mathrm{Ag} / \mathrm{Na}_{2} \mathrm{Ti}_{6} \mathrm{O}_{13}$ catalysts were much improved by optimizing several conditions such as the flux in a flux method, and the loading method and the loading amount of silver cocatalyst. Second, the reasons for the nonstoichiometric $\mathrm{O}_{2}$ evolution in the initial period were clarified.

\section{Experimental}

\subsection{Sample preparation}

The $\mathrm{Na}_{2} \mathrm{Ti}_{3} \mathrm{O}_{7}$ sample was prepared by a solid state reaction (SSR) method reported in the literature [39]. The precursors $\left(\mathrm{Na}_{2} \mathrm{CO}_{3}\right.$ (Kishida): $\mathrm{TiO}_{2}$ (rutile, Kojundo)=1:3) were mixed for 30 minutes in an alumina mortar and calcined at $1073 \mathrm{~K}$ for $20 \mathrm{~h}$, followed by additional grinding at room temperature and heating at $1073 \mathrm{~K}$ for another $20 \mathrm{~h}$. Although it was examined to prepare another $\mathrm{Na}_{2} \mathrm{Ti}_{3} \mathrm{O}_{7}$ sample by a flux method, no sample showing XRD patterns was obtained.

For the preparation of another $\mathrm{Na}_{2} \mathrm{Ti}_{6} \mathrm{O}_{13}$ sample in the SSR method, the precursors were mixed for 30 minutes in an alumina mortar, where the molar ratio of $\mathrm{Na}_{2} \mathrm{CO}_{3}$ to $\mathrm{TiO}_{2}$ was 1:6. The mixture was put into a platinum crucible, heated in an electric muffle furnace with a rate of $200 \mathrm{~K} \mathrm{~h}^{-1}$ to $1273 \mathrm{~K}$, held at this temperature for $10 \mathrm{~h}$, and then cooled at a rate of $-100 \mathrm{~K} \mathrm{~h}^{-1}$ to $773 \mathrm{~K}$, followed by being naturally cooled to room temperature in the furnace. This sample is referred to as $\mathrm{NTO}(\mathrm{SSR})$. Several $\mathrm{Na}_{2} \mathrm{Ti}_{6} \mathrm{O}_{13}$ samples were prepared also in a flux method [27]. The precursors, $\mathrm{Na}_{2} \mathrm{CO}_{3}$ and $\mathrm{TiO}_{2}$, and a flux reagent such as $\mathrm{NaCl}, \mathrm{NaF}, \mathrm{NaBr}, \mathrm{NaI}$ (Nacalai Tesque), or $\mathrm{KCl}$ (Kishida), were mixed for 20 minutes in an alumina mortar and heated in the same temperature program as mentioned above, and the solute $\left(\mathrm{Na}_{2} \mathrm{Ti}_{6} \mathrm{O}_{13}\right)$ to the flux in the molten mixture was $1: 1$. The obtained powder was thoroughly washed with hot water ( $353 \mathrm{~K}$ ) for 15 minutes and filtrated, and this washing step was repeated 3 times to remove the remained residual salt, then dried at $323 \mathrm{~K}$ for 24 hours. The $\mathrm{Na}_{2} \mathrm{Ti}_{6} \mathrm{O}_{13}$ samples prepared by different fluxes are referred to as $\mathrm{NTO}($ flux $)$ such as $\mathrm{NTO}(\mathrm{NaCl})$.

Ag cocatalyst was loaded on the sodium titanate samples by a photodeposition method (PD), a chemical reduction method (CR), or an impregnation method (IMP). In the PD method, $1 \mathrm{~g}$ of the $\mathrm{Na}_{2} \mathrm{Ti}_{3} \mathrm{O}_{7}$ or $\mathrm{Na}_{2} \mathrm{Ti}_{6} \mathrm{O}_{13}$ sample in 150 $\mathrm{mL}$ of ion-exchanged water was irradiated using a $300 \mathrm{~W}$ xenon lamp (PE300BUV) for 30 minutes with magnetically stirring. Then $50 \mathrm{~mL}$ of $\mathrm{CH}_{3} \mathrm{OH}$ and a required amount of $\mathrm{AgNO}_{3}$ were added and the suspension was stirred for 30 minutes without irradiation. Based on the loading amount of Ag over different samples, it was irradiated for 2-6 hours, where the light intensity was measured to be $22 \mathrm{~mW} \mathrm{~cm}^{-2}$ at $254 \pm 10 \mathrm{~nm}$ in wavelength. The obtained suspension was filtrated and washed by hot water (353K) 3 times, and dried at $323 \mathrm{~K}$ for 24 hours. In the CR method, the $\mathrm{Na}_{2} \mathrm{Ti}_{6} \mathrm{O}_{13}$ sample (1g) was suspended in $50 \mathrm{~mL}$ of an aqueous solution of $\mathrm{AgNO}_{3}(0.295 \mathrm{M})$, followed by the dropwise addition of an aqueous $\mathrm{NaPH}_{2} \mathrm{O}_{2}$ solution $(0.295 \mathrm{M}, 315 \mu \mathrm{L})$ into the suspension. After stirring the mixture at $353 \mathrm{~K}$ for $2 \mathrm{~h}$, it was washed by ion-exchanged water, and it was filtered and dried at room temperature. In the IMP method, $1 \mathrm{~g}$ of the $\mathrm{Na}_{2} \mathrm{Ti}_{6} \mathrm{O}_{13}$ sample was suspended in $100 \mathrm{~mL}$ of ion exchange water with the desired amount of $\mathrm{AgNO}_{3}$, followed by evaporation at $353 \mathrm{~K}$ to remove water, drying for $24 \mathrm{~h}$ at $373 \mathrm{~K}$, and calcination at $723 \mathrm{~K}$ for $2 \mathrm{~h}$ in air. The Ag-loaded $\mathrm{NTO}(\mathrm{NaCl})$ samples are referred to as $\mathrm{Ag} / \mathrm{NTO}(\mathrm{NaCl}, \mathrm{PD}), \mathrm{Ag} / \mathrm{NTO}(\mathrm{NaCl}, \mathrm{CR})$, and 
$\mathrm{Ag} / \mathrm{NTO}(\mathrm{NaCl}, \mathrm{IMP})$.

\subsection{Characterization}

The loading amount of Ag on the samples was evaluated by X-ray fluorescence analysis with an EDX-8000 (Shimadzu) using an experimentally obtained calibration curve. The crystal structure of the samples was determined by powder X-ray diffraction with a Lab X XRD-6000 (Shimazu). Morphologies of the samples were observed by scanning electron microscopy (SEM) image with a JSM-890 (JEOL). Diffuse reflectance (DR) UV-Vis spectrum was recorded by a V-670 (JASCO). The bandgap was estimated according to the Davis-Mott equation using the KubelkaMunk function $\mathrm{F}(\mathrm{R} \infty)$ obtained from the diffuse-reflectance spectrum [42]. The Brunauer-Emmett-Teller (BET) specific surface area was calculated from the amount of $\mathrm{N}_{2}$ adsorption at $77 \mathrm{~K}$, which was measured by a Monosorb (Quantachrome).

\subsection{Photocatalytic reaction test}

The photocatalytic activity tests of $\mathrm{CO}_{2}$ reduction with water were carried out using a bubbling-flow system with an inner-irradiation-type reaction vessel [24], which were the most different points of the reaction conditions from those in the previous study [27]. The Ag-loaded sodium titanate sample ( $0.2 \mathrm{~g})$ was dispersed in ion-exchanged water (350 mL) containing $0.5 \mathrm{M} \mathrm{NaHCO}_{3}$ by magnetically stirring. Then, $\mathrm{CO}_{2}$ was bubbled into the solution at a flow rate of $15 \mathrm{~mL} \mathrm{~min}{ }^{-1}$ without irradiation for 1.5 hours. The photocatalytic reaction was conducted using a $100 \mathrm{~W}$ highpressure mercury lamp with $44 \mathrm{~mW} \mathrm{~cm}{ }^{-2}$ measured at $254 \pm 10 \mathrm{~nm}$ in wavelength. The reaction temperature was 290 $\mathrm{K}$. The evolution rate of the products $\left(\mathrm{CO}, \mathrm{H}_{2}\right.$, and $\left.\mathrm{O}_{2}\right)$ in the outlet from the reactor were determined by using an on-line gas chromatograph (Shimadzu, GC-8A, TCD, Shincarbon ST column, argon carrier).

\subsection{Evaluation of oxidative byproducts in aqueous solution}

To know whether hydrogen peroxide $\left(\mathrm{H}_{2} \mathrm{O}_{2}\right)$ was formed or not, the aqueous solution after the photocatalytic reaction test was sampled and the conventional starch-iodine test was examined using KI reagent and starch. Assuming that all photoformed holes were consumed to produce $\mathrm{H}_{2} \mathrm{O}_{2}$ in this system, the equivalent $\mathrm{H}_{2} \mathrm{O}_{2}$ reagent (31.9 $\left.\mu \mathrm{mol} \mathrm{L}{ }^{-1}\right)$ was prepared and used as a reference.

To confirm the formation of hypochlorous acid $(\mathrm{HClO})$ in the aqueous solutions after the photocatalytic reactions, a conventional DPD test was employed $[39,43,44]$. When the $N$ - $N$-diethyl-p-phenylenediamine (DPD) reagent is added to a solution containing HClO, a red oxidant of DPD rapidly formed through the stoichiometric reaction. The DPD solution was prepared by dissolving $0.1 \mathrm{~g}$ of the DPD reagent (Wako), which is a mixture of DPD sulfate and $\mathrm{Na}_{2} \mathrm{SO}_{4}$, in $5.0 \mathrm{~mL}$ of a phosphate buffer solution $(\mathrm{pH}=6.5) .1 .0 \mathrm{~mL}$ of the prepared DPD solution was added to 5.0 $\mathrm{mL}$ of the sample solution, and was shaken for $20 \mathrm{~s}$. The transmittance spectrum was measured immediately using a UV-vis spectrometer (JASCO V-670) in a transmission mode. 


\section{Results and discussions}

\subsection{Sodium titanates}

Two types of sodium titanates, sodium trititanate $\left(\mathrm{Na}_{2} \mathrm{Ti}_{3} \mathrm{O}_{7}\right)$ and sodium hexatitanate $\left(\mathrm{Na}_{2} \mathrm{Ti}_{6} \mathrm{O}_{13}\right)$, were fabricated. Fig. 1 shows XRD patterns of the obtained samples with those from the database (ICSD\#15463 for $\mathrm{Na}_{2} \mathrm{Ti}_{3} \mathrm{O}_{7}$ [45] and ICSD\#23877 for $\mathrm{Na}_{2} \mathrm{Ti}_{6} \mathrm{O}_{13}$ [46]) as references. The patterns of the $\mathrm{Na}_{2} \mathrm{Ti}_{3} \mathrm{O}_{7}(\mathrm{SSR})$ sample and the $\mathrm{Na}_{2} \mathrm{Ti}_{6} \mathrm{O}_{13}$ samples (Fig. 1a, 1b, and 1c) were consistent with the reference data, respectively. Since no diffraction lines corresponding to other impurity phases were observed, it was confirmed that two types of pure sodium titanates, $\mathrm{Na}_{2} \mathrm{Ti}_{3} \mathrm{O}_{7}$ and $\mathrm{Na}_{2} \mathrm{Ti}_{6} \mathrm{O}_{13}$, were correctly fabricated. It is noted that the distribution of the diffraction line intensity of the $\mathrm{NTO}(\mathrm{NaCl})$ sample prepared with the $\mathrm{NaCl}$ flux are different from that of the $\mathrm{NTO}(\mathrm{SSR})$ sample and the reference. And the intensities of some diffraction lines were also quite different, for example, the intensity of the line at $11.86^{\circ}$ corresponding to (200) plane in the pattern of the $\mathrm{NTO}(\mathrm{NaCl})$ sample was much higher than that for the others, implying that the $\mathrm{Na}_{2} \mathrm{Ti}_{6} \mathrm{O}_{13}$ crystals prepared by the flux method have an anisotropic morphology.

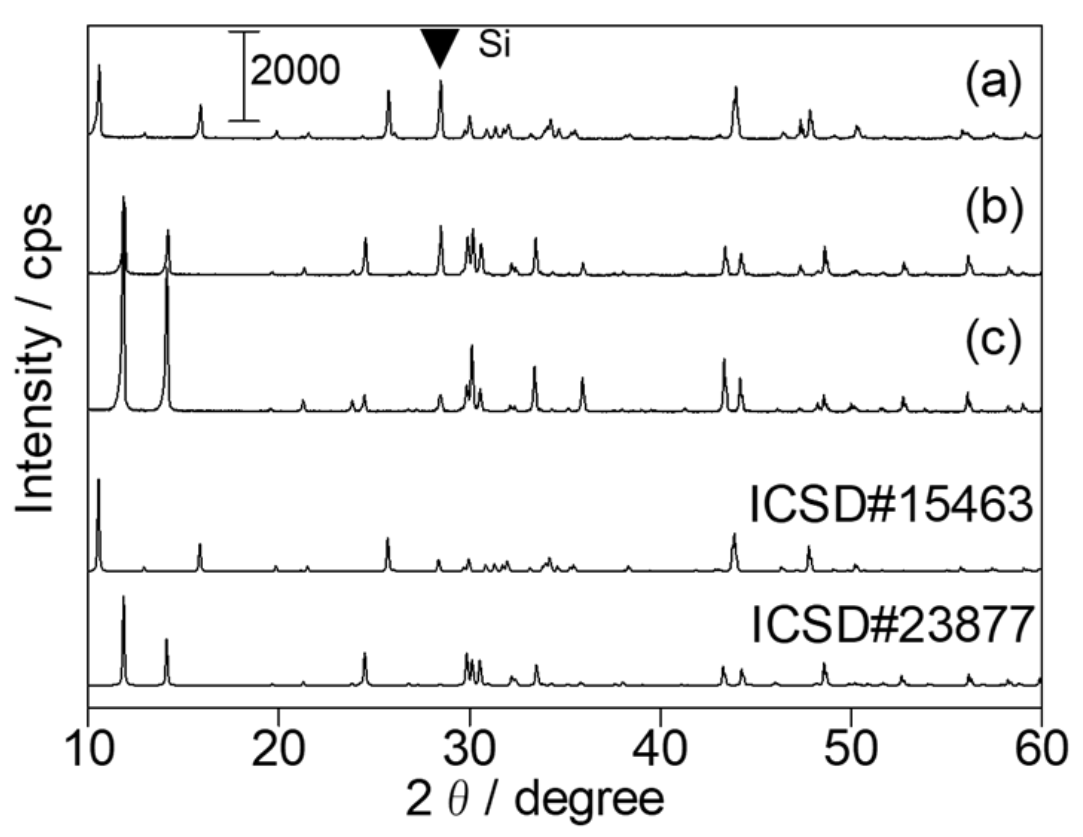

Fig. 1. XRD patterns of the samples; (a) the $\mathrm{Na}_{2} \mathrm{Ti}_{3} \mathrm{O}_{7}$ (SSR) sample, (b) the NTO(SSR) sample, and $(\mathrm{c})$ the $\mathrm{NTO}(\mathrm{NaCl})$ sample. Silicon powder mixed to calibrate the angle showed a diffraction indicated by a closed triangle. The patterns from the ICSD database are also shown, ICSD\#15463 for $\mathrm{Na}_{2} \mathrm{Ti}_{3} \mathrm{O}_{7}$ and ICSD\#23877 for $\mathrm{Na}_{2} \mathrm{Ti}_{6} \mathrm{O}_{13}$.

Fig. 2 shows the SEM images. The $\mathrm{Na}_{2} \mathrm{Ti}_{3} \mathrm{O}_{7}$ (SSR) sample consisted of small roundish rod-like or roundish particles with almost uniformed size less than $1 \mu \mathrm{m}$ (Fig. 2a), while the NTO(SSR) sample showed more irregular shape of particles, most of which were smaller than $1 \mu \mathrm{m}$ but some of which were much larger (Fig. 2b). On the other hand, the $\mathrm{NTO}(\mathrm{NaCl})$ sample consisted of anisotropic rod-like crystal structure covered with facets and crystal size was larger than $2 \mu \mathrm{m}$ (Fig. 2c). This confirms that the molten salt can enhance the crystallization and regulate the 
crystal growth of each facet to form the unique morphology. It is known that this effect depends on the property of the cation such as $\mathrm{Na}^{+}, \mathrm{K}^{+}$in the molten flux [27].
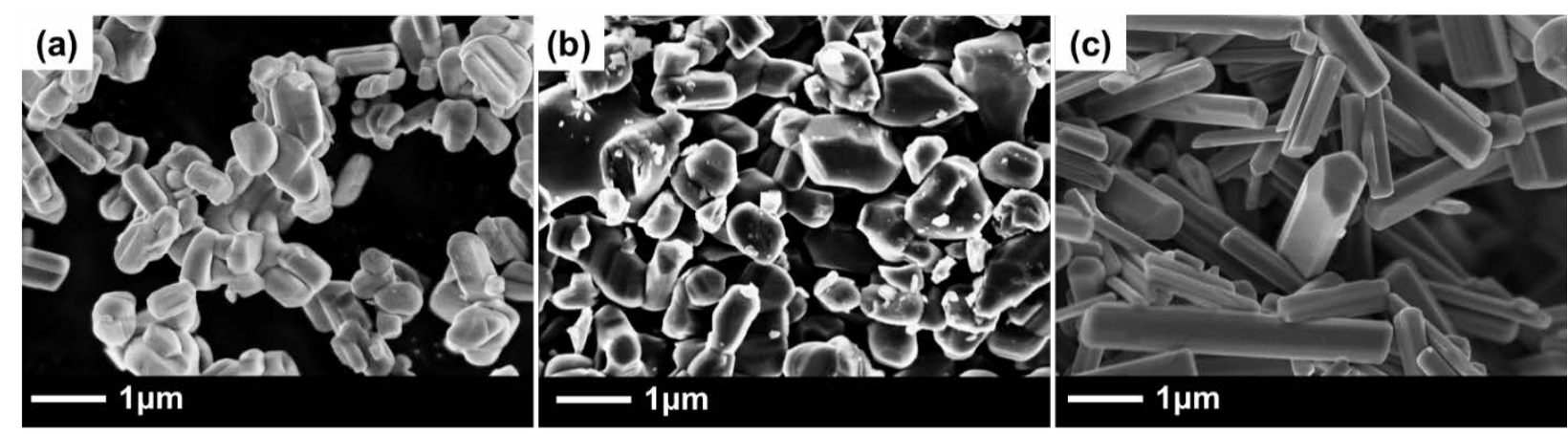

Fig. 2 SEM images of the prepared samples; (a) the $\mathrm{Na}_{2} \mathrm{Ti}_{3} \mathrm{O}_{7}$ (SSR) sample, (b) the NTO (SSR) sample, and (c) the NTO (NaCl) sample.

As shown in Table 1, the specific surface areas of the $\mathrm{Na}_{2} \mathrm{Ti}_{3} \mathrm{O}_{7}(\mathrm{SSR})$ sample, the NTO(SSR) sample and the NTO $(\mathrm{NaCl})$ sample were measured to be 2.58, 3.91, and $5.17 \mathrm{~m}^{2} \mathrm{~g}^{-1}$, respectively. Furthermore, Fig. 3A shows DR UVvisible spectra of these samples, which give information for the electronic band structure. The $\mathrm{Na}_{2} \mathrm{Ti}_{3} \mathrm{O}_{7}\left(\mathrm{SSR}_{\text {) sample }}\right.$ showed an absorption band less than $320 \mathrm{~nm}$ in wavelength, while the NTO(SSR) and NTO(NaCl) samples showed the absorption edge at $350.7 \mathrm{~nm}$ and $351.2 \mathrm{~nm}$, respectively. The estimated bandgap for the $\mathrm{Na}_{2} \mathrm{Ti}_{3} \mathrm{O}_{7}\left(\mathrm{SSR}_{\text {) sample }}\right.$ was $3.88 \mathrm{eV}$, which was slightly bigger than $3.54 \mathrm{eV}$ for the $\mathrm{NTO}(\mathrm{SSR})$ sample and $3.53 \mathrm{eV}$ for the $\mathrm{NTO}(\mathrm{NaCl})$ sample.

Table 1 Properties of the prepared $\mathrm{Na}_{2} \mathrm{Ti}_{3} \mathrm{O}_{7}$ and $\mathrm{Na}_{2} \mathrm{Ti}_{6} \mathrm{O}_{13}$ samples.

\begin{tabular}{|c|c|c|c|c|c|c|}
\hline Entry & Sample & $\begin{array}{c}\text { Preparation } \\
\text { method }\end{array}$ & Crystal phase ${ }^{\mathrm{a}}$ & $\begin{array}{l}\text { Specific surface } \\
\text { area }^{b} / m^{2} g^{-1}\end{array}$ & $\begin{array}{c}\text { Bandgap }^{c} \\
\text { / eV }\end{array}$ & $\begin{array}{l}\text { Loading amount } \\
\text { of } \mathrm{Ag}^{\mathrm{d}}(\mathrm{wt} \%)\end{array}$ \\
\hline 1 & $\mathrm{Na}_{2} \mathrm{Ti}_{3} \mathrm{O}_{7}(\mathrm{SSR})$ & SSR & $\mathrm{Na}_{2} \mathrm{Ti}_{3} \mathrm{O}_{7}$ & 2.58 & 3.88 & 0.99 \\
\hline 2 & NTO(SSR) & SSR & $\mathrm{Na}_{2} \mathrm{Ti}_{6} \mathrm{O}_{13}$ & 3.91 & 3.54 & 0.99 \\
\hline 3 & NTO(NaCl) & Flux method & $\mathrm{Na}_{2} \mathrm{Ti}_{6} \mathrm{O}_{13}$ & 5.17 & 3.53 & 0.93 \\
\hline
\end{tabular}

XRF measurements confirmed the loading amount of the Ag cocatalyst on these three samples by the PD method to be almost $1 \mathrm{wt} \%$ of Ag cocatalyst on each sample as expected (Table 1). In the DR UV-vis spectra of the Agloaded samples (Fig. 3B), the surface plasmon resonance (SPR) band of the Ag nanoparticles was similarly observed for the $\mathrm{Ag} / \mathrm{NTO}(\mathrm{SSR})$ sample and the $\mathrm{Ag} / \mathrm{NTO}(\mathrm{NaCl})$ sample, while no such band was observed for the $\mathrm{Ag} / \mathrm{Na}_{2} \mathrm{Ti}_{3} \mathrm{O}_{7}$ sample. This difference would originate from the state of the Ag species added on the sodium titanate samples. For the $\mathrm{Ag} / \mathrm{Na}_{2} \mathrm{Ti}_{3} \mathrm{O}_{7}$ sample, the bandgap was shifted from $3.88 \mathrm{eV}$ to $3.49 \mathrm{eV}$, where the $\mathrm{Ag}^{+}$cations could be easy inserted and exchange to the $\mathrm{Na}^{+}$between the titanate layered structure of the $\mathrm{Na}_{2} \mathrm{Ti}_{3} \mathrm{O}_{7}$ sample. This indicated that 
Ag nanoparticles exist only on the NTO samples.
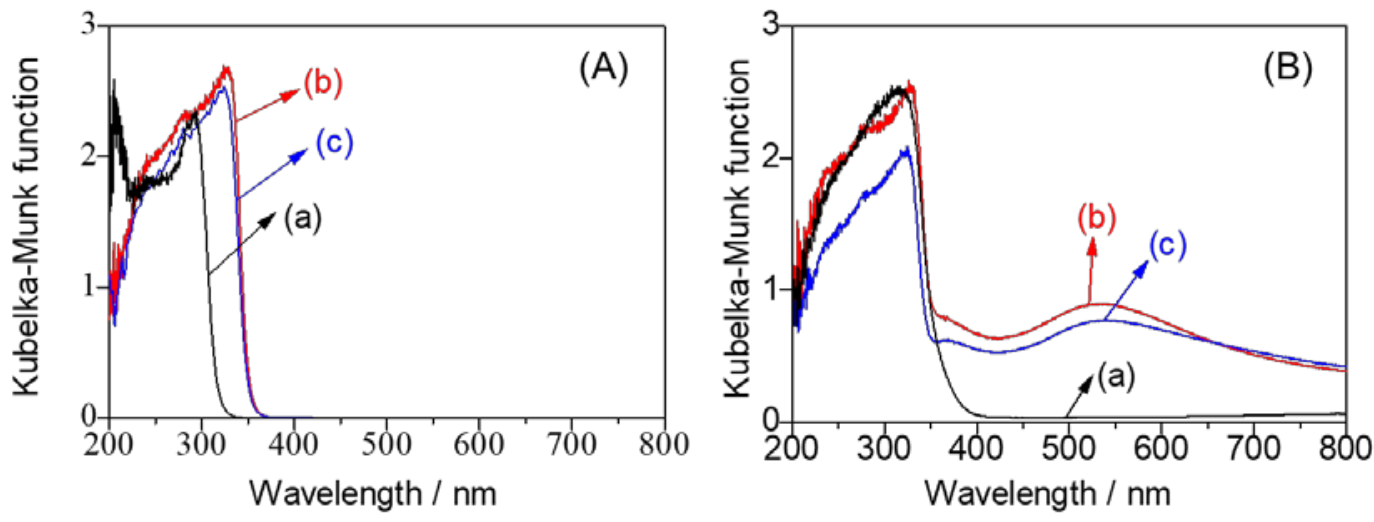

Fig. 3. DR UV-visible spectra of the prepared samples loaded without (A) and with 1 wt $\%$ Ag cocatalyst (B), the $\mathrm{Na}_{2} \mathrm{Ti}_{3} \mathrm{O}_{7}\left(\mathrm{SSR}_{\text {) }}\right.$ sample (a), the NTO(SSR) sample (b), and the NTO(NaCl) sample (c). Ag cocatalyst was loaded by the PD method.

Fig. 4 shows the results of the photocatalytic reaction tests, i.e., the time course of the formation rates of the products and the selectivity toward $\mathrm{CO}$ evolution $\left(S_{\mathrm{CO}}\right)$ in the photocatalytic conversion of $\mathrm{CO}_{2}$ with water over the three Ag-loaded samples. The three samples exhibited the photocatalytic activity to produce $\mathrm{CO}, \mathrm{O}_{2}$ and $\mathrm{H}_{2}$. First, when compared the two samples prepared by the SSR method, the $\mathrm{Ag} / \mathrm{Na}_{2} \mathrm{Ti}_{3} \mathrm{O}_{7}(\mathrm{SSR})$ and $\mathrm{Ag} / \mathrm{NTO}(\mathrm{SSR})$ samples (Figs. 4a and $4 \mathrm{~b}$ ), the most obvious difference between them was the product selectivity, i.e., the former exhibited high selectivity to form $\mathrm{H}_{2}$ and the latter predominantly produced $\mathrm{CO}$ with high selectivity such as $S_{\mathrm{CO}}=75-90 \%$. These samples have some different properties such as compositions, crystal structures, band structure and also the state of the Ag cocatalyst. Especially, the former exhibited no obvious SPR band while the latter clearly showed, suggesting the Ag species exist as a dispersed or oxidized form in the former sample and as nanoparticles in the latter sample. Considering the well-known function of the Ag nanoparticles as a cocatalyst to produce $\mathrm{CO}$, it seems reasonable that the $\mathrm{Ag} / \mathrm{Na}_{2} \mathrm{Ti}_{3} \mathrm{O}_{7}(\mathrm{SSR})$ sample without any $\mathrm{Ag}$ nanoparticles cannot produce $\mathrm{CO}$ and the Ag/NTO(SSR) sample can produce CO selectively.

Next, among the two $\mathrm{Na}_{2} \mathrm{Ti}_{6} \mathrm{O}_{13}$ samples, the $\mathrm{Ag} / \mathrm{NTO}(\mathrm{NaCl})$ sample prepared by a flux method gave the higher formation rate of both $\mathrm{CO}$ and $\mathrm{H}_{2}$ than the $\mathrm{Ag} / \mathrm{NTO}$ (SSR) sample (Fig. 4c). This shows an advantage of the flux method to give the active $\mathrm{Na}_{2} \mathrm{Ti}_{6} \mathrm{O}_{13}$ photocatalyst for this photocatalytic reaction. The $\mathrm{CO}$ formation rate over the present $\mathrm{Ag} / \mathrm{NTO}(\mathrm{NaCl})$ sample with $1 \mathrm{wt} \%$ of $\mathrm{Ag}$ cocatalyst in the present reaction condition was $3.3 \mu \mathrm{mol} \mathrm{h}^{-1}$ at 5 $\mathrm{h}$, which is ca. 10 times higher than that over the best Ag/NTO sample in the previous study [23]. The both $\mathrm{Ag} / \mathrm{NTO}(\mathrm{NaCl})$ and Ag/NTO(SSR) samples showed similarly high CO selectivity (Fig. 4b and 4c). This is consistent with the fact that the Ag cocatalyst nanoparticles as the cocatalyst on the NTO surface showed similar SPR band in the UV-vis spectra (Fig. 3).

On both the Ag/NTO samples prepared by the SSR method and the flux method, the formation rate of $\mathrm{CO}$ and $\mathrm{H}_{2}$ decreased and the $S_{\mathrm{Co}}$ increased with irradiation time, which would be due to the aggregation of the deposited $\mathrm{Ag}$ particles as mentioned later and also in the previous study [23]. The $\mathrm{O}_{2}$ evolution was also observed in the current reaction condition although the ratio of consumed electron and holes was not consistent, $R\left(\mathrm{e}^{-} / \mathrm{h}^{+}\right)>1$, which will be 
discussed later.

According to the results in this section, further studies were carried out on the Ag/NTO samples prepared by the flux method.

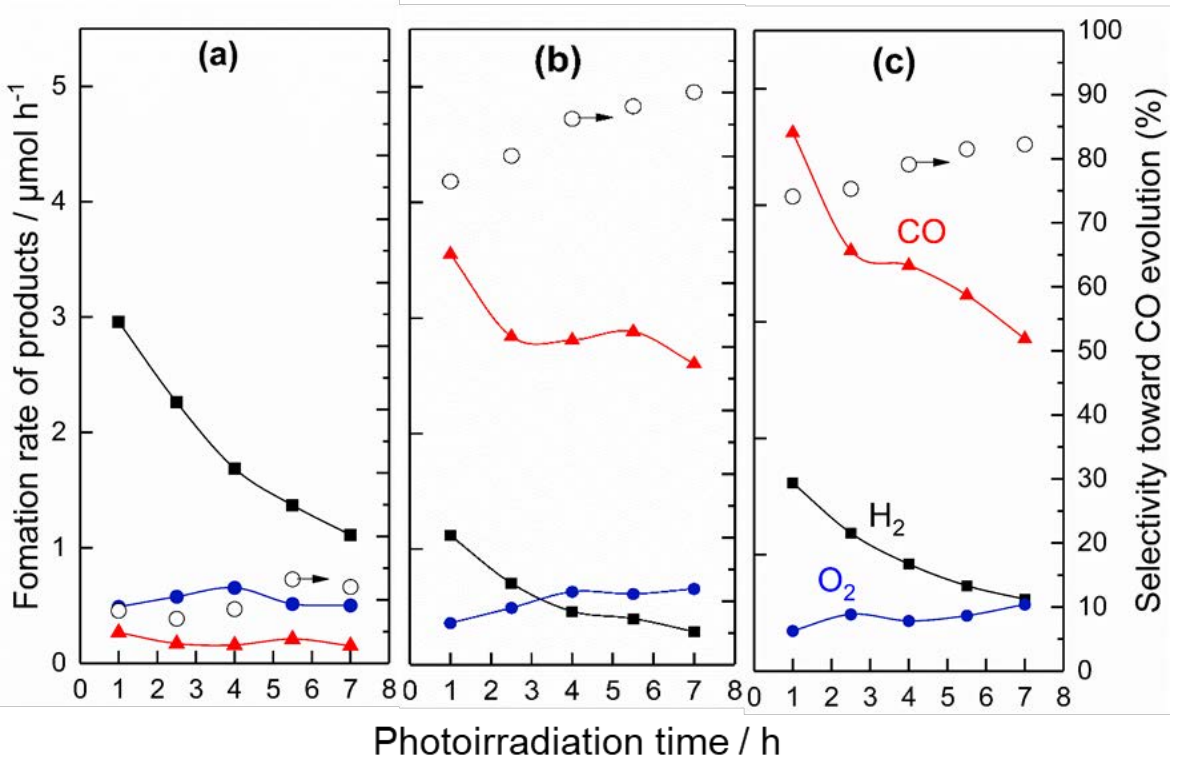

Fig. 4. Formation rates of $\mathrm{CO}$ (red triangles), $\mathrm{H}_{2}$ (black squares), and $\mathrm{O}_{2}$ (blue circles), and the selectivity toward $\mathrm{CO}$ evolution (open circles) in the photocatalytic conversion of $\mathrm{CO}_{2}$ with water over the prepared samples loaded with 1 wt\% Ag cocatalyst loaded by the PD method, (a) the $\mathrm{Ag} / \mathrm{Na}_{2} \mathrm{Ti}_{3} \mathrm{O}_{7}$ (SSR) sample, (b) the $\mathrm{Ag} / \mathrm{NTO}(\mathrm{SSR}$ ), and (c) the $\mathrm{Ag} / \mathrm{NTO}(\mathrm{NaCl})$ sample.

\subsection{Sodium hexatitanate prepared by the flux method}

It was well known that molten salt as a flux can regulate the crystal growth to provide a unique morphology of the crystals. In the previous study, some kinds of the salts such as $\mathrm{LiCl}, \mathrm{NaCl}, \mathrm{KCl}$, and $\mathrm{CaCl}_{2}$ were examined for the preparation of NTO samples, and it was found that the $\mathrm{LiCl}$ and $\mathrm{CaCl}_{2}$ salts are not suitable for the preparation of $\mathrm{Na}_{2} \mathrm{Ti}_{6} \mathrm{O}_{13}$ phase while only the $\mathrm{KCl}$ and $\mathrm{NaCl}$ fluxes can promote the formation of the hexagonal rod-like crystals [27]. In order to figure out the effect of $\mathrm{NaCl}$ flux, another series of experiments were also conducted in this study. Four catalysts were prepared in the flux method using various fluxes such as $\mathrm{NaF}, \mathrm{NaCl}, \mathrm{NaBr}$, and $\mathrm{NaI}$. Pure $\mathrm{Na}_{2} \mathrm{Ti}_{6} \mathrm{O}_{13}$ crystals were confirmed by the XRD patterns (Fig. 5) for these NTO samples except for the NTO(NaI) sample. It is noted that the distribution of the diffraction line intensity of the NTO(NaI) sample are different from those of the $\mathrm{NTO}(\mathrm{NaCl})$ and $\mathrm{NTO}(\mathrm{NaBr})$ samples and the reference, especially the ratio the intensity of the line at $11.86^{\circ}$ corresponding to (200) plane and $14.12^{\circ}$ corresponding to (-201) plane. In the UV spectra (Fig. S1), the $\mathrm{NTO}(\mathrm{NaF})$ sample exhibited a small shift of the absorption edge, and the $\mathrm{NTO}(\mathrm{NaBr})$ sample showed small absorbance of visible light. Furthermore, the SEM images show that the morphologies of NTO with different fluxes were quite different from each other, and it is notable that the $\mathrm{NTO}(\mathrm{NaCl})$ shown in Fig. 2c gave much clear morphology with uniform rod-like particles than others shown in Fig .6. This may be due to the effect of the difference in the electronegativity of the halogen atoms, i.e., 3.98, 3.16, 2.96, and 2.66 [47] for F, Cl, $\mathrm{Br}$ and I, respectively, or the melting point of the fluxes, i.e., 1266, 1074, 1028, and $933 \mathrm{~K}$ for $\mathrm{NaF}, \mathrm{NaCl}, \mathrm{NaBr}$, $\mathrm{NaI}$, respectively. Although 
the reason could not be clearly mentioned, it is the fact that the $\mathrm{NaCl}$ is quite suitable for the fabrication of the rodlike NTO particles.

The results of the photocatalytic activity tests of these samples loaded with Ag cocatalyst were shown in Fig. 7. It is quite clear that the sample prepared with $\mathrm{NaCl}$ exhibited the highest activity for $\mathrm{CO}$ evolution. It is also noted that the $R\left(\mathrm{e}^{-} / \mathrm{h}^{+}\right)$with the sample prepared with $\mathrm{NaCl}$ was 4.6 at the initial reaction stage, which is much higher than other samples. This suggests that the $\mathrm{NaCl}$ flux may be beneficial to the preparation of the photocatalyst for $\mathrm{CO}$ production but the chloride anion $\left(\mathrm{Cl}^{-}\right)$may be not good for sufficient oxygen evolution due to the reactivity to hole as discussed later.

In literature, it was reported that a mixture of two fluxes could enhance the activity of $\mathrm{Sr}_{2} \mathrm{KTa}_{5} \mathrm{O}_{15}$ photocatalyst [48], which motivated us to fabricate five samples with the different mixing ratio of $\mathrm{NaCl}$ and $\mathrm{KCl}$ fluxes in this study (Fig. S2). The results are mentioned in the ESI. The conclusion is, however, that the sample prepared with the pure $\mathrm{NaCl}$ flux exhibited the best photocatalytic activity among the examined NTO samples (Fig. S3).

In this section, it was concluded the NTO sample prepared by a flux method with the pure $\mathrm{NaCl}$ flux is the optimized one for the reduction of $\mathrm{CO}_{2}$ in the improved reaction condition. It was clarified that both the use of flux and the property of the flux much affected the shape of the particles and also the photocatalytic activity.

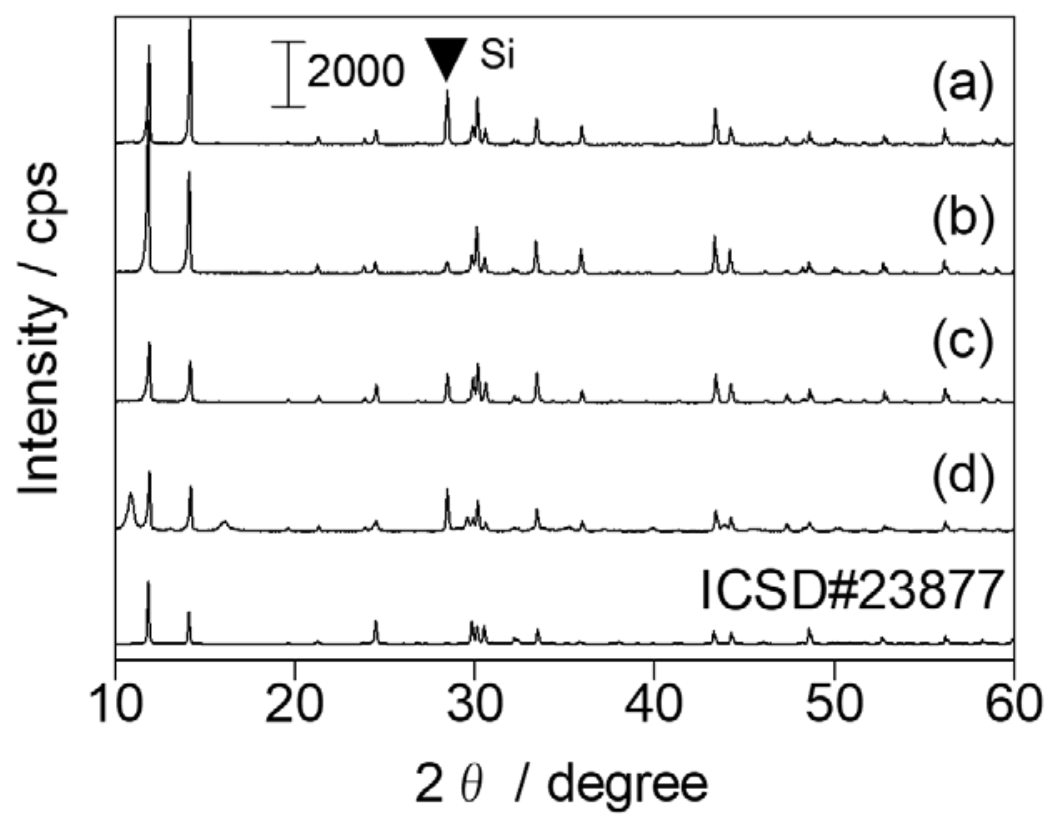

Fig. 5. XRD patterns of the prepared NTO samples with different flux; (a) NaF, (b) $\mathrm{NaCl}$, (c) $\mathrm{NaBr}$, (d) NaI, and ICSD\#23877 for $\mathrm{Na}_{2} \mathrm{Ti}_{6} \mathrm{O}_{13}$. Silicon powder mixed to calibrate the angle showed a diffraction indicated by a closed triangle. 

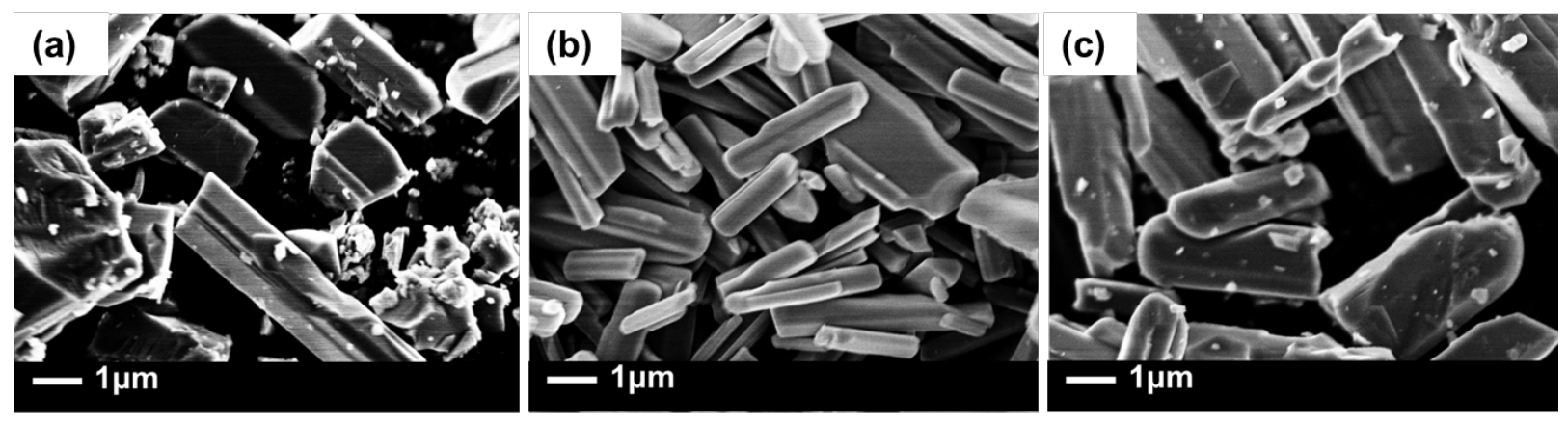

Fig. 6. SEM images of the prepared NTO samples with various fluxes; (a) $\mathrm{NaF}$, (b) $\mathrm{NaBr}$, and (c) $\mathrm{NaI}$.

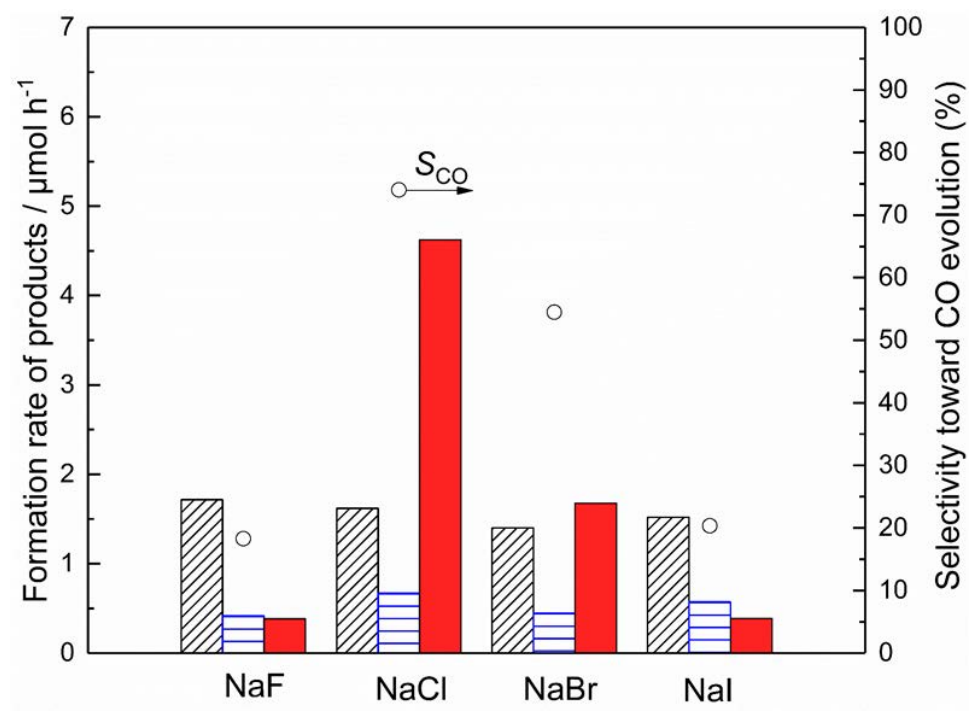

Fig. 7. Formation rates of $\mathrm{CO}$ (red bar), $\mathrm{H}_{2}$ (black bar), and $\mathrm{O}_{2}$ (blue bar) and the $S_{\mathrm{CO}}$ evolution (open circles) in the photocatalytic reaction tests with the $\mathrm{Ag} / \mathrm{NTO}(\mathrm{NaX})(\mathrm{X}: \mathrm{F}, \mathrm{Cl}, \mathrm{Br}$, and I) samples prepared by using various fluxes. The values were recorded after 1 hour's irradiation. Ag cocatalyst was loaded by the PD method.

\subsection{Ag cocatalysts}

The Ag cocatalyst has been employed for the $\mathrm{CO}$ production in the heterogeneous photocatalytic reduction of $\mathrm{CO}_{2}$ with water. The loading method and loading amount of the Ag cocatalyst have been reported to affect the state of Ag nanoparticles on the photocatalyst and thus the photocatalytic activity and selectivity [20,49-53]. In the current study, the effects of the loading amount of Ag cocatalyst and loading method on the photocatalytic activity of the $\mathrm{NTO}(\mathrm{NaCl})$ samples for $\mathrm{CO}_{2}$ conversion were investigated.

Fig. 8 shows the SEM images of the samples with different loading amount of the Ag cocatalyst prepared by the PD method. It was quite clear that the size of Ag particles became bigger with increasing the loading amount. The particle size of Ag over the $0.1 \mathrm{wt} \% \mathrm{Ag} / \mathrm{NTO}(\mathrm{NaCl}, \mathrm{PD}), 0.5 \mathrm{wt} \% \mathrm{Ag} / \mathrm{NTO}(\mathrm{NaCl}, \mathrm{PD})$ and $1.0 \mathrm{wt} \% \mathrm{Ag} / \mathrm{NTO}(\mathrm{NaCl}, \mathrm{PD})$ 
samples were ca. 12-18 nm, 15-25 nm and 21-32 nm respectively. The Ag particles aggregated when the loading amount was over $1.0 \mathrm{wt} \%$. In the DR UV-vis spectra Fig. S4, with the increase of the Ag loading amount, the band due to the Ag nanoparticles became larger and red-shifted, suggesting that the size of the deposited Ag particles increased, which consistent with the phenomenon observed in the SEM images.
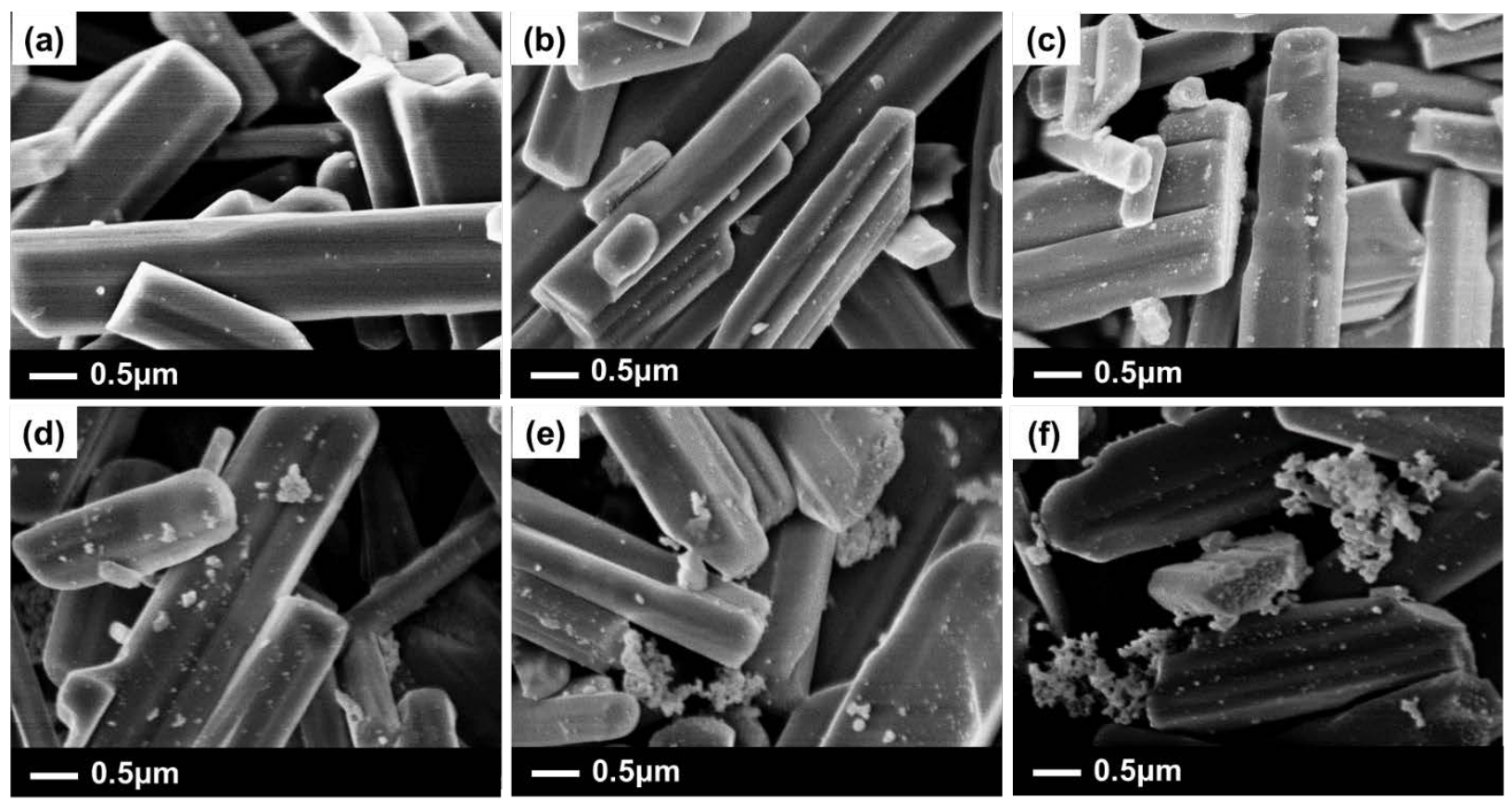

Fig. 8. SEM images of the Ag/NTO(NaCl,PD) samples with different loading amount of Ag, (a) 0.1 wt $\%$, (b) 0.5 $w t \%$, (c) $1.0 \mathrm{wt} \%$, (d) $2.0 \mathrm{wt} \%$, (e) $3.0 \mathrm{wt} \%$, and (f) $4.0 \mathrm{wt} \%$, prepared by the PD method.

Fig. 9 shows the formation rate of the products during the photocatalytic conversion of $\mathrm{CO}_{2}$ with water over the $\mathrm{Ag} / \mathrm{NTO}(\mathrm{NaCl}, \mathrm{PD})$ samples with different loading amount of Ag cocatalyst. Both the CO production rate and the $S_{\mathrm{CO}}$ increased and with increasing the loading amounts from $0 \mathrm{wt} \%$ to $1.0 \mathrm{wt} \%$, suggesting that the Ag cocatalyst enhances the $\mathrm{CO}$ formation and leads to decrease the active sites for $\mathrm{H}_{2}$ evolution on the NTO surface. As a result, $1.0 \mathrm{wt} \%$ of Ag cocatalyst was the optimized mounts for providing the highest CO formation rate $\left(4.6 \mu \mathrm{mol} \mathrm{h}{ }^{-1}\right)$ and the highest selectivity toward CO evolution (74\%). On the other hand, the photocatalytic activity decreased above $1.0 \mathrm{wt} \%$ while $S_{\mathrm{CO}}$ became constant to be $60 \%$. This would be related to the aggregation of the Ag particles observed in the SEM images (Fig. 8), i.e., the surface area of Ag cocatalyst and its contact to the NTO surface would decrease due to the aggregation. 


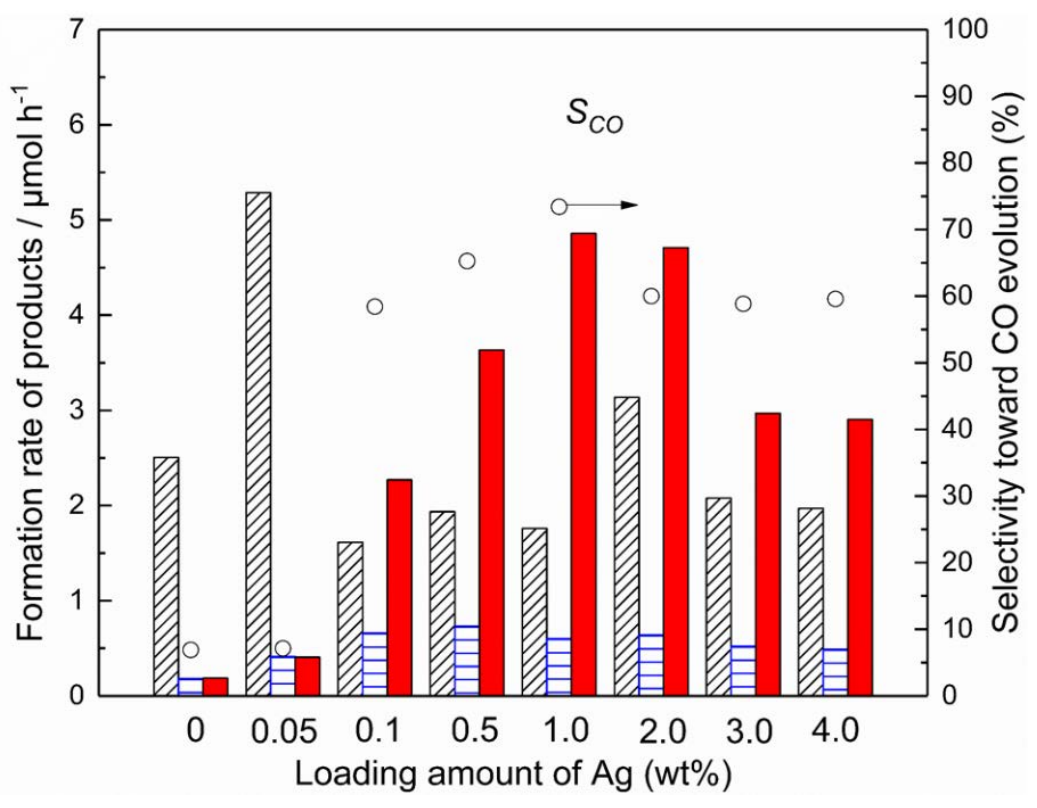

Fig. 9. Formation rates of $\mathrm{CO}$ (red bar), $\mathrm{H}_{2}$ (black bar), and $\mathrm{O}_{2}$ (blue bar) and the $S_{\mathrm{CO}}$ (open circles) in the photocatalytic conversion of $\mathrm{CO}_{2}$ over the $\mathrm{Ag} / \mathrm{NTO}(\mathrm{NaCl}, \mathrm{PD})$ samples with different loading amount of $\mathrm{Ag}$ cocatalyst. The formation rates were recorded after 1 hour's irradiation. Photocatalyst powder: $0.2 \mathrm{~g}$, reaction solution volume: $350 \mathrm{~mL}$, additive: $0.5 \mathrm{M} \mathrm{NaHCO}_{3}$, Ag loading method: photodeposition method, $\mathrm{CO}_{2}$ flow rate:

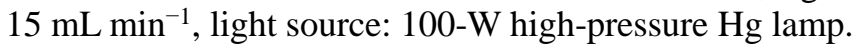

The SEM images of the $1 \mathrm{wt} \% \mathrm{Ag} / \mathrm{NTO}$ samples prepared by three methods are shown in Fig. 10, which were taken before and after the photocatalytic reaction tests. As synthesized, it was discovered that both the size of the Ag nanoparticles and their surface distribution on the three samples were quite different from each other (Figs. 10a, 10b, and 10c). When it was loaded by the PD method, some part of Ag nanoparticles with a size of 21-32 nm were mainly stabilized on the long facets of the rod-like crystals (Fig. 10a). During the photodeposition of Ag nanoparticles, $\mathrm{Ag}^{+}$ cations are reduced by the photoexcited electron, meaning that the long facets would be the reductive facets that provide electrons predominantly. On the sample deposited by CR method, many fine Ag nanoparticles were more uniformly scattered on all the facets of the NTO crystals with the smallest size (10-15 nm) among the three samples (Fig. 10b). In this method, the adsorbed $\mathrm{Ag}^{+}$cation would be chemically reduced to form Ag nanoparticles on each facet. The IMP method provided a little larger Ag particle with a size of 70-75 nm (Fig. 10c). Probably, the procedure of drying up and calcination would make the $\mathrm{Ag}^{+}$cations and $\mathrm{Ag}$ oxide species get together to form larger silver oxide particles. As shown in Fig. 11A, this different phenomenon was also consistent with the DR UV-vis spectra of three samples. Characteristic bands assignable to Ag nanoparticles were observed for the $\mathrm{Ag} / \mathrm{NTO}(\mathrm{NaCl}, \mathrm{CR})$ sample and the $\mathrm{Ag} / \mathrm{NTO}(\mathrm{NaCl}, \mathrm{PD})$ sample, but not for the $\mathrm{Ag} / \mathrm{NTO}(\mathrm{NaCl}, \mathrm{IMP})$ sample. And compared with the $\mathrm{Ag} / \mathrm{NTO}(\mathrm{NaCl}, \mathrm{PD})$ sample, the band over $\mathrm{Ag} / \mathrm{NTO}(\mathrm{NaCl}, \mathrm{CR})$ was a bit blue shifted, which indicated smaller size of Ag particles were fabricated by the CR method as shown in the SEM images (Figs. 10a and 10b). 

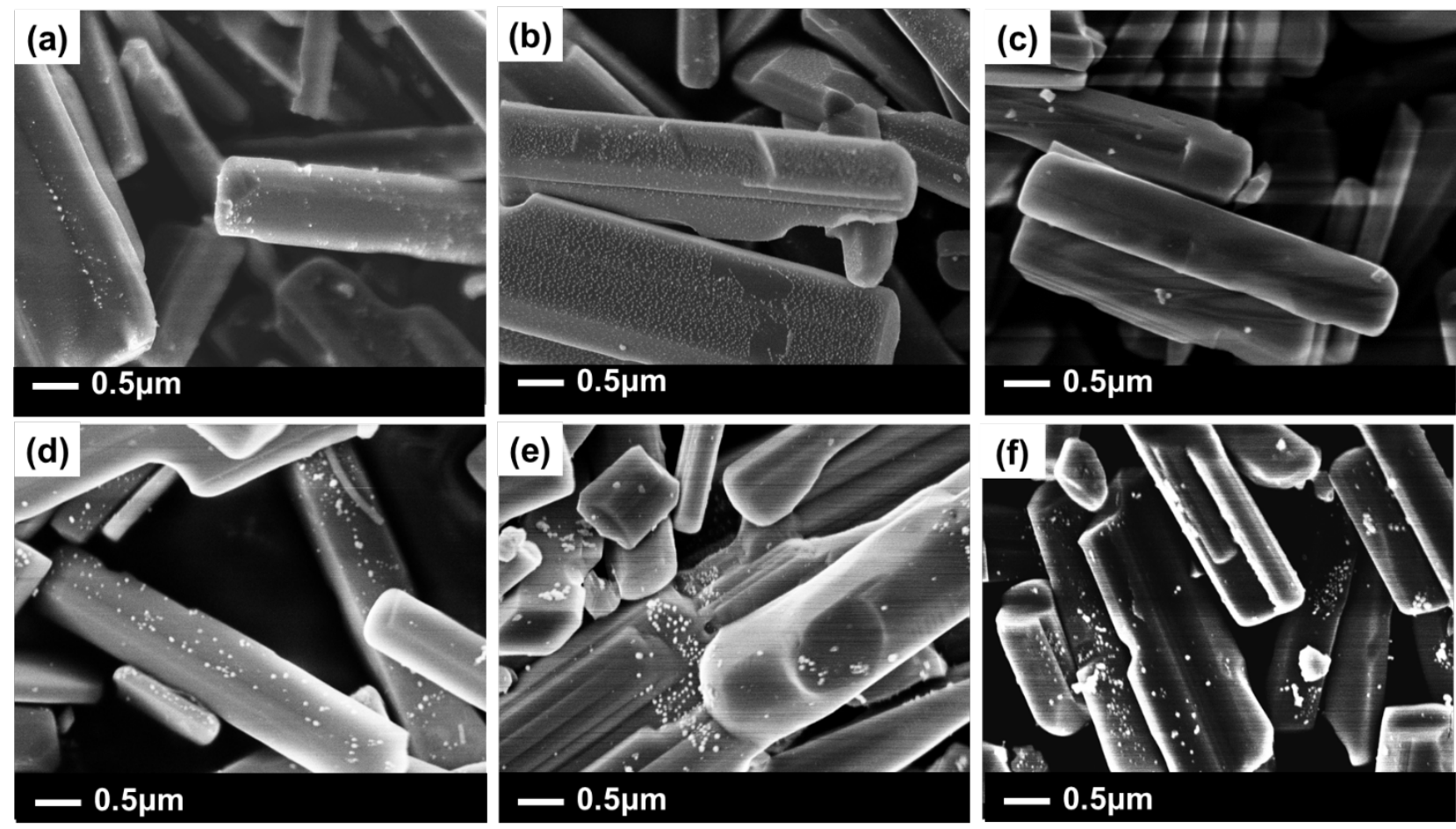

Fig. 10 SEM images of the Ag/NTO(NaCl) samples prepared by (a, d) PD, (b, e) CR, and (c, f) IMP methods, (a-c) before and (d-f) after the photocatalytic reaction tests for $7 \mathrm{~h}$.

After the photocatalytic reaction tests, however, the size and the distribution of the Ag particles became quite similar to each other (Figs. 10d-f), and almost similar bands assignable to Ag cocatalyst were observed for these samples (Fig. 11B). These results indicate that the Ag particles of these samples aggregated. In details, in the $\mathrm{Ag} / \mathrm{NTO}(\mathrm{NaCl}, \mathrm{PD})$ and $\mathrm{Ag} / \mathrm{NTO}(\mathrm{NaCl}, \mathrm{CR})$ samples, the particle sizes of the Ag nanoparticles became slightly larger, while the silver Ag particles were reduced and dispersed on the $\mathrm{Ag} / \mathrm{NTO}(\mathrm{NaCl}, \mathrm{IMP})$ sample. This means that the rearrangement of the $\mathrm{Ag}$ atoms takes place through the $\mathrm{Ag}^{0} / \mathrm{Ag}^{+}$redox cycles as proposed in the previous study [23], and this would be one of the reasons for the variation of the production rates with time during the photocatalytic reaction tests mentioned below.
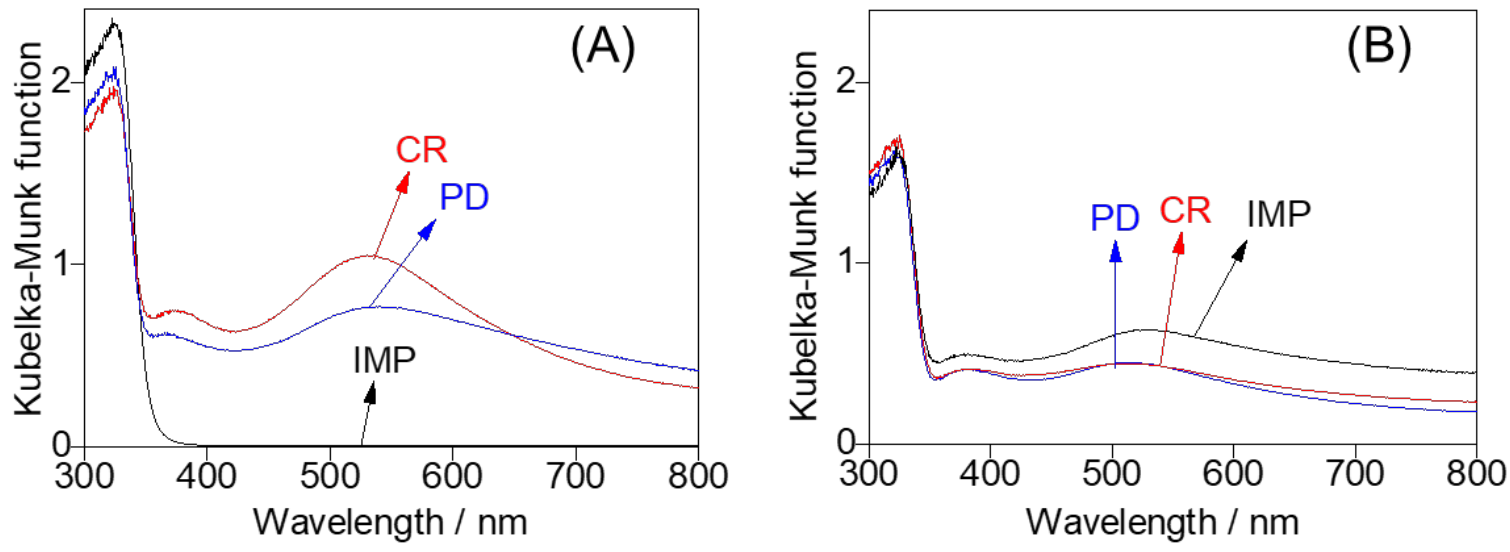

Fig. 11. DR UV- spectra of the Ag/NTO(NaCl) samples loaded with 1 wt\% Ag by the PD, CR, and IMP methods, 
recorded before (A) and after (B) photocatalytic reaction for $7 \mathrm{~h}$.

Fig. 12 shows the formation rates of $\mathrm{CO}, \mathrm{H}_{2}$, and $\mathrm{O}_{2}$ in the photocatalytic reaction tests for the conversion of $\mathrm{CO}_{2}$ using the $\mathrm{Ag} / \mathrm{NTO}(\mathrm{NaCl})$ samples, on which $1 \mathrm{wt} \%$ of Ag cocatalyst was loaded by the PD, CR, and IMP methods. Among the photocatalysts, the Ag/NTO(NaCl,PD) and Ag/NTO(NaCl,CR) samples exhibited higher photocatalytic activity than the $\mathrm{Ag} / \mathrm{NTO}(\mathrm{NaCl}, \mathrm{IMP})$ sample. And the $\mathrm{CO}$ production rate over the $\mathrm{Ag} / \mathrm{NTO}(\mathrm{NaCl}, \mathrm{PD})$ sample was 4.6 $\mu \mathrm{mol} \mathrm{h}{ }^{-1}$ after irradiation for one hour, which was higher than the other samples. Since it is proposed that the PD method tends to form the Ag nanoparticles on the reductive facets of the rod-like $\mathrm{NTO}(\mathrm{NaCl}) \mathrm{crystals}$, the $\mathrm{Ag}$ nanoparticles would efficiently receive the photo-excited electrons and promote the photocatalytic reduction of $\mathrm{CO}_{2}$ to produce CO. The CO production rate gradually decreased from the start and became $2.8 \mu \mathrm{mol} \mathrm{h}{ }^{-1}$ after $7 \mathrm{~h}$ over the Ag/NTO(NaCl,PD) sample. The aggregation of Ag cocatalyst particles was one responsible reason for this deactivation. As shown in the SEM images (Fig. 10), the Ag particle sizes of the Ag/NTO(NaCl,PD) and Ag/NTO(NaCl,CR) samples became to 25-30 nm after 7 hours' reaction test, which could decrease the active sites of the Ag cocatalyst surface and the contact to the NTO surface, and thus reduce the photocatalytic activity.

In the previous reaction conditions [27], the formation of $\mathrm{O}_{2}$ was not observed initially. Even though it became actually observable 24 hours later, it was still not enough production rate compared to the formation rates of reductive products. In the present study, the $\mathrm{O}_{2}$ evolution was observed even at the initial stage. However, the stoichiometric formation rate of $\mathrm{O}_{2}$ was still not obtained during the initial period over the $\mathrm{Ag} / \mathrm{NTO}(\mathrm{NaCl}, \mathrm{PD})$ sample, where $R\left(\mathrm{e}^{-} / \mathrm{h}^{+}\right)$was 3.0 after 7 hours' irradiation. This matter will be discussed in the next section.

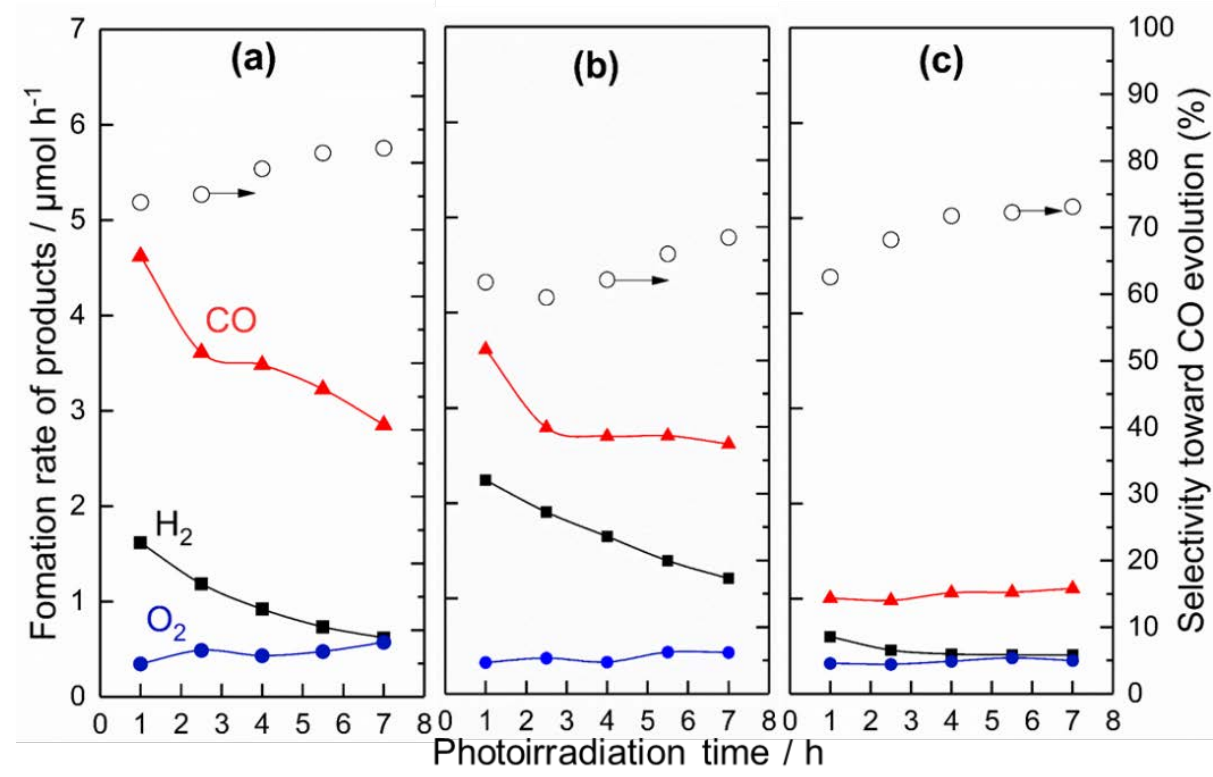

Fig. 12 Formation rates of $\mathrm{CO}$ (red triangles), $\mathrm{H}_{2}$ (black squares), and $\mathrm{O}_{2}$ (blue circles) and the selectivity toward $\mathrm{CO}$ evolution (black circle) in the photocatalytic conversion of $\mathrm{CO}_{2}$ with water over the Ag/NTO(NaCl) sample, on which 1 wt\% of Ag cocatalyst was loaded by the PD (a), CR (b) and IMP (c) methods. Photocatalyst powder: $0.2 \mathrm{~g}$, reaction solution volume: $350 \mathrm{~mL}$, additive: $0.5 \mathrm{M} \mathrm{NaHCO}, \mathrm{Ag}$ loading amount: $1.0 \mathrm{wt} \%, \mathrm{CO}_{2}$ flow rate: $15 \mathrm{~mL} \mathrm{~min}^{-1}$, light source: 100-W high-pressure Hg lamp. 


\subsection{Oxidation reaction}

The oxygen evolution reaction (OER) is one of the major challenges in the water splitting as well as $\mathrm{CO}_{2}$ reduction with water. Many papers have been reported to improve the OER by combined the co-catalysts with some metal oxides such as manganese oxide, and so on [54-59]. And in literature, it is sometimes found that photocatalysts for water splitting produce only $\mathrm{H}_{2}$ without enough evolution of $\mathrm{O}_{2}\left(\mathrm{H}_{2} / \mathrm{O}_{2}>2\right)$ [31,60]. This phenomenon may be explained by the difficulty of $\mathrm{O}_{2}$ evolution due to the high overpotential of $\mathrm{O}_{2}$ formation, which originates from trapping and stabilization of positive charge by the surface sites [28-30]. However, if the consumption of holes does not take place, the reductive reaction to produce $\mathrm{CO}$ and $\mathrm{H}_{2}$ will also stop soon. Since the formation of reductive products underwent over $8 \mathrm{~h}$ in Fig. 9, the oxidation reaction should take place. Here, three possibilities are discussed as the reasons for this phenomenon.

The first possibility is that water might be oxidized to hydrogen peroxide [61] (Eq. 8).

$2 \mathrm{H}_{2} \mathrm{O}+2 \mathrm{~h}^{+} \rightarrow \mathrm{H}_{2} \mathrm{O}_{2}+2 \mathrm{H}^{+}$

To confirm this possibility, the starch iodine reaction test was carried out. It showed a negative result for the solution after the photocatalytic reaction test as described in the supplementary information, i.e., the color change was not observed as shown in Fig. S5. Thus, it can be mentioned that this was at least not the dominant reason.

The second possibility is that residual chloride anion $\left(\mathrm{Cl}^{-}\right)$on the surface of the $\mathrm{NTO}(\mathrm{NaCl}, \mathrm{PD})$ photocatalyst, originating from the $\mathrm{NaCl}$ flux, might react with the photoformed hole to form hypochlorite $\left(\mathrm{ClO}^{-}\right)$shown in eq. 9 , which competitively consume hole and reduce the oxidation of water to form $\mathrm{O}_{2}$.

$\mathrm{Cl}^{-}+\mathrm{H}_{2} \mathrm{O}+2 \mathrm{~h}^{+} \rightarrow \mathrm{ClO}^{-}+2 \mathrm{H}^{+}$

$2 \mathrm{ClO}^{-}+h v(\lambda<400 \mathrm{~nm}) \rightarrow \mathrm{O}_{2}+2 \mathrm{Cl}^{-}$

The DPD tests [39] were conducted for the filtrated solutions after the photocatalytic reaction tests with the $\mathrm{Ag} / \mathrm{NTO}(\mathrm{SSR}, \mathrm{PD})$ sample and the $\mathrm{Ag} / \mathrm{NTO}(\mathrm{NaCl}, \mathrm{PD})$ sample as well as a distilled water as a reference, and the positive results were obtained on the solution separated from the solution with the Ag/NTO(NaCl,PD) sample (Fig. S6). Thus, it was clarified that $\mathrm{Cl}^{-}$residue was oxidized to $\mathrm{ClO}^{-}$, which competitively consumed holes to reduce the formation of $\mathrm{O}_{2}$. The detected amount of $\mathrm{ClO}^{-}$, calculated by the standard curve reported in the literature [42], was quite small $(0.8 \mu \mathrm{mol})$ after 7 hours' irradiation. This may be due to the decomposition of hypochlorite $\left(\mathrm{ClO}^{-}\right)$shown in the eq. 10 since the high-pressure mercury lamp was used in the current system. With the increasing concentration of $\mathrm{ClO}^{-}$in the solution, the reaction rate of eq.9 would decrease while the rate of eq.10 would increase. And when the reaction rate of the eq. 10 increased to a half of that of the eq. 9, the stoichiometric amount of $\mathrm{O}_{2}$ was supposed to be produced in the current system. 

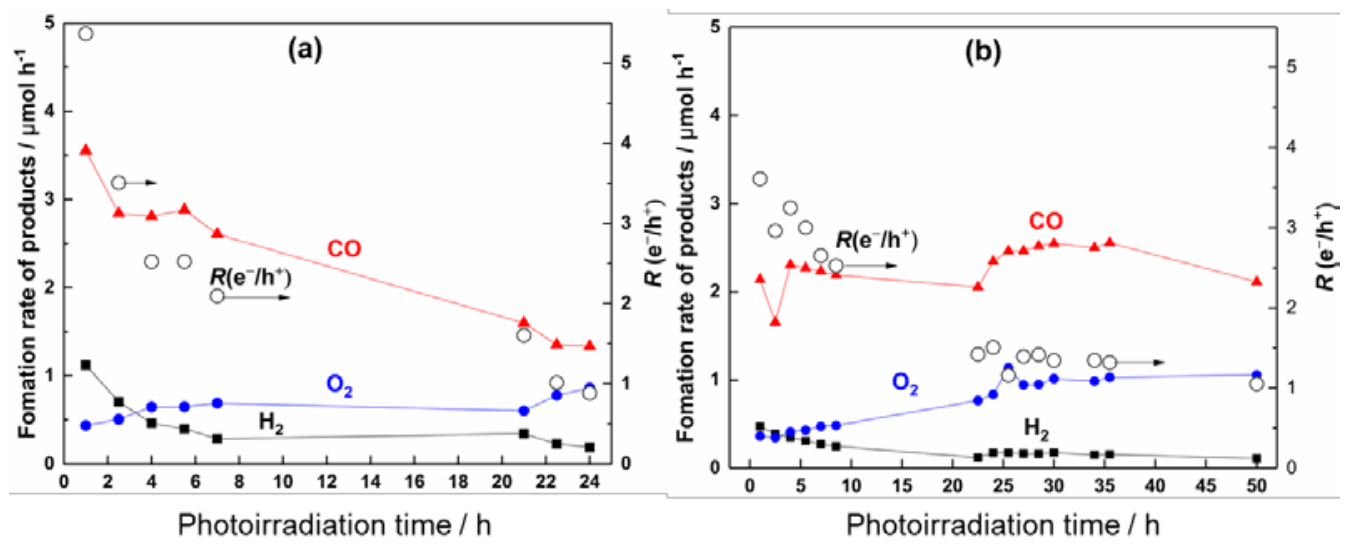

Fig. 13. Formation rates of $\mathrm{CO}$ (red triangles), $\mathrm{H}_{2}$ (black squares), and $\mathrm{O}_{2}$ (blue circles) and the $R\left(\mathrm{e}^{-} / \mathrm{h}^{+}\right)$] (open circle in the photocatalytic conversion of $\mathrm{CO}_{2}$ with water by using (a) the $\mathrm{Ag} / \mathrm{NTO}(\mathrm{SSR}, \mathrm{PD}$ ) sample and (b) the $\mathrm{Ag} / \mathrm{NTO}(\mathrm{NaCl}, \mathrm{PD})$ sample. Photocatalyst powder: $0.2 \mathrm{~g}$, reaction solution volume: $350 \mathrm{~mL}$, additive: $0.5 \mathrm{M}$ $\mathrm{NaHCO}_{3}$, Ag loading method: photodeposition method, $\mathrm{CO}_{2}$ flow rate: $15 \mathrm{~mL} \mathrm{~min}{ }^{-1}$, light source: 100 -W highpressure Hg lamp.

The third possibility is that the produced $\mathrm{O}_{2}$ might be adsorbed on the surface of catalysts to some extent especially under photoirradiation, since the photoadsorption of oxygen on $\mathrm{TiO}_{2}$ was reported [32,33]. Fig. 13 shows the formation rates of $\mathrm{CO}, \mathrm{H}_{2}$, and $\mathrm{O}_{2}$ and the consumed $\mathrm{e}^{-} / \mathrm{h}^{+}$ratio, $R\left(\mathrm{e}^{-} / \mathrm{h}^{+}\right)$, in the photocatalytic conversion of $\mathrm{CO}_{2}$ over the two samples, Ag/NTO(SSR,PD) and Ag/NTO(NaCl,PD). Even in the case of the reaction test with the $\mathrm{Ag} / \mathrm{NTO}(\mathrm{SSR}, \mathrm{PD})$ sample, the $\mathrm{O}_{2}$ evolution increased with irradiation time, and the $R\left(\mathrm{e}^{-} / \mathrm{h}^{+}\right)$became to be 1.0 after 22.5 hours. Since this sample should be free from chloride anion, the initially insufficient $\mathrm{O}_{2}$ evolution could be explained by not the oxidation of chloride anion but the photoadsorption of $\mathrm{O}_{2}$ on the surface of catalysts. After 22.5 hours, the $\mathrm{O}_{2}$ photoadsorption on the surface would be saturated and no more photoadsorption would take place.

Even for the Ag/NTO(NaCl,PD) samples, the ratio of $\mathrm{e}^{-} / \mathrm{h}^{+}$became gradually close to be 1.0 after about 50 hours. In this state, not only the $\mathrm{O}_{2}$ photoadsorption but also the composition of the chloride $\left(\mathrm{Cl}^{-}\right)$should be taken into consideration. The concentration of hypochlorite $\left(\mathrm{ClO}^{-}\right)$anion would also become constant in the reaction solution to give $\mathrm{O}_{2}$ evolution.

As a summary of this section, two possible reasons for the non-stoichiometric amount of $\mathrm{O}_{2}$ evolution can be proposed as follows, i.e., the oxidation of chloride residues and the photoadsorption of $\mathrm{O}_{2}$ on the surface.

\section{Conclusion}

In this study, two remained problems in the previous work, one of which is low activity toward CO evolution and low selectivity, and the other is nonstoichiometric $\mathrm{O}_{2}$ evolution, were much improved and explained, respectively.

First, it was found that the Ag/NTO sample, with $1.0 \mathrm{wt} \%$ of Ag cocatalyst loaded by a photodeposition method, exhibited the highest $\mathrm{CO}$ production rate $\left(4.6 \mu \mathrm{mol} \mathrm{h}^{-1}\right)$ and the highest CO selectivity (74\%) among the examined samples in the current reaction conditions. These values are more than 29 times higher production rate and more than 2.7 times higher selectivity than those obtained in the previous study, which would originate from the optimization of the photocatalyst and the improved reaction conditions. In addition, among three Ag/NTO samples, on which 1.0 
wt\% of the Ag cocatalyst nanoparticles were loaded by different methods, the Ag/NTO sample provided by the PD method gave the highest activity and selectivity for $\mathrm{CO}_{2}$ reduction. Since the PD method tends to form the metallic Ag nanoparticles on the reductive facets of the rod-like NTO crystals, which can efficiently promote the CO evolution.

Second, although the evolution rate of $\mathrm{O}_{2}$ was not enough in the induction period, it increased with time and reached to the stoichiometric formation ratio of the oxidative and reductive products after a long time, such as 24 or $50 \mathrm{~h}$, depending on the samples. Furthermore, it was confirmed that the chloride residues and the photoadsorption of $\mathrm{O}_{2}$ on the surface are responsible for the insufficient $\mathrm{O}_{2}$ evolution less than stoichiometric ratio among the products at the initial period.

The present comprehensive study has provided some solutions to improve both the CO evolution and the $S_{\mathrm{CO}}$ over the $\mathrm{Na}_{2} \mathrm{Ti}_{6} \mathrm{O}_{13}$ sample. Further studies are very necessary both to improve the photocatalytic activity and enhance the $\mathrm{O}_{2}$ evolution at the initial time.

\section{Acknowledgments}

This work was carried out as the joint research program of the Artificial Photosynthesis, Osaka City University, and also financially supported by a Grant-in-Aid for Scientific Research on Innovative Areas "All Nippon Artificial Photosynthesis Project for Living Earth (An Apple)” (No. 25107515) from the Japan Society for the Promotion of Science (JSPS), and the Program for Element Strategy Initiative for Catalysts \& Batteries (ESICB), commissioned by the MEXT of Japan.

\section{References}

[1] M. Mikkelsen, M. Jorgensen, F.C. Krebs, The teraton challenge. A review of fixation and transformation of carbon dioxide, Energy Environ. Sci. 3 (2010) 43-81.

[2] J.L. White, M.F. Baruch, J.E. Pander, Y. Hu, I.C. Fortmeyer, J.E. Park, T. Zhang, K. Liao, J. Gu, Y. Yan, T.W. Shaw, E. Abelev, A.B. Bocarsly, Light-Driven heterogeneous reduction of carbon dioxide: photocatalysts and photoelectrodes, Chem. Rev. 115 (2015) 12888-12935.

[3] B. Kumar, M. Llorente, J. Froehlich, T. Dang, A. Sathrum, C.P. Kubiak, Photochemical and photoelectrochemical reduction of $\mathrm{CO}_{2}$, Annu. Rev. Phys. Chem. 63 (2012) 541-569.

[4] X. Chang, T. Wang, J. Gong, $\mathrm{CO}_{2}$ photo-reduction: Insights into $\mathrm{CO}_{2}$ activation and reaction on surfaces of photocatalysts, Energy Environ. Sci. 9 (2016) 2177-2196.

[5] J. Low, J. Yu, W. Ho, Graphene-based photocatalysts for $\mathrm{CO}_{2}$ reduction to solar fuel, J. Phys. Chem. Lett. 6 (2015) 4244-4251.

[6] M. Halmann, Photoelectrochemical reduction of aqueous carbon dioxide on p-type gallium phosphide in liquid junction solar cells, Nature. 275 (1978) 115-116.

[7] M. Asadi, B. Kumar, A. Behranginia, B.A. Rosen, A. Baskin, N. Repnin, D. Pisasale, P. Phillips, W. Zhu, R. Haasch, R.F. Klie, P. Kral, J. Abiade, A. Salehi-Khojin, Robust carbon dioxide reduction on molybdenum disulphide edges, Nat. Commun. 5 (2014) 1-8.

[8] J.C. Hemminger, R. Carr, G.A. Somorjai, The photoassisted reaction of gaseous water and carbon dioxide adsorbed on the $\mathrm{SrTiO}_{3}$ (111) crystal face to form methane, Chem. Phys. Lett. 57 (1978) 100-104.

[9] S.N. Habisreutinger, L. Schmidt-Mende, J.K. Stolarczyk, Photocatalytic reduction of $\mathrm{CO}_{2}$ on $\mathrm{TiO}_{2}$ and other semiconductors, Angew. Chemie - Int. Ed. 52 (2013) 7372-7408.

[10] T. Arai, S. Sato, T. Kajino, T. Morikawa, Solar $\mathrm{CO}_{2}$ reduction using $\mathrm{H}_{2} \mathrm{O}$ by a semiconductor/metal-complex hybrid photocatalyst: enhanced efficiency and demonstration of a wireless system using $\mathrm{SrTiO}_{3}$ photoanodes, Energy Environ. Sci. 6 (2013) 1274-1282.

[11] S. Sato, T. Arai, T. Morikawa, K. Uemura, T.M. Suzuki, H. Tanaka, T. Kajino, Selective $\mathrm{CO}_{2}$ conversion to formate conjugated with $\mathrm{H}_{2} \mathrm{O}$ oxidation utilizing semiconductor/complex hybrid photocatalysts, J. Am. Chem. Soc. 133 (2011) 15240-15243. 
[12] O. Ishitani, C. Inoue, Y. Suzuki, T. Ibusuki, O. Ishitani|, C. Inoue, Y. Suzuki, T. Ibusuki, Photocatalytic reduction of carbon dioxide to methane and acetic acid by an aqueous suspension of metal-deposited $\mathrm{TiO}_{2}$, $\mathrm{J}$. Photochem. Photobiol. A Chem. 72 (1993) 269-271.

[13] A. Nakada, T. Nakashima, K. Sekizawa, K. Maeda, O. Ishitani, Visible-light-driven $\mathrm{CO}_{2}$ reduction on a hybrid photocatalyst consisting of a Ru (II) binuclear complex and a Ag-loaded TaON in aqueous solutions, Chem. Sci. 7 (2016) 4364-4371.

[14] S.C. Roy, O.K. Varghese, M. Paulose, C. a Grimes, Toward solar fuels : photocatalytic hydrocarbons, ACS Nano. 4 (2010) 1259-1278.

[15] K. Iizuka, T. Wato, Y. Miseki, K. Saito, A. Kudo, Photocatalytic reduction of carbon dioxide over Ag cocatalyst-loaded $\mathrm{ALa}_{4} \mathrm{Ti}_{4} \mathrm{O}_{15}(\mathrm{~A}=\mathrm{Ca}, \mathrm{Sr}$, and $\mathrm{Ba}$ ) using water as a reducing reagent., J. Am. Chem. Soc. 133 (2011) 20863-20868.

[16] M. Yamamoto, T. Yoshida, N. Yamamoto, T. Nomoto, Y. Yamamoto, S. Yagi, H. Yoshida, Photocatalytic reduction of $\mathrm{CO}_{2}$ with water promoted by Ag clusters in $\mathrm{Ag} / \mathrm{Ga}_{2} \mathrm{O}_{3}$ photocatalysts, J. Mater. Chem. A. 3 (2015) 16810-16816.

[17] N. Yamamoto, T. Yoshida, S. Yagi, Z. Like, T. Mizutani, S. Ogawa, H. Nameki, H. Yoshida, The inuence of the preparing method of a $\mathrm{Ag} / \mathrm{Ga}_{2} \mathrm{O}_{3}$ catalyst on its activity for photocatalytic reduction of $\mathrm{CO}_{2}$ with water, E-Journal Surf. Sci. Nanotechnol. 12 (2014) 263-268.

[18] M. Yamamoto, T. Yoshida, N. Yamamoto, H. Yoshida, S. Yagi, In-Situ FT-IR study on the mechanism of $\mathrm{CO}_{2}$ reduction with water over metal (Ag or $\mathrm{Au}$ ) loaded $\mathrm{Ga}_{2} \mathrm{O}_{3}$ photocatalysts, E-Journal Surf. Sci. Nanotechnol. 12 (2014) 299-303.

[19] H. Tatsumi, K. Teramura, Z. Huang, Z. Wang, H. Asakura, S. Hosokawa, T. Tanaka, Enhancement of CO evolution by modification of $\mathrm{Ga}_{2} \mathrm{O}_{3}$ with rare-Earth elements for the photocatalytic conversion of $\mathrm{CO}_{2}$ by $\mathrm{H}_{2} \mathrm{O}$, Langmuir. (2017) 33, 49(2017), 13929-13935.

[20] R. Pang, K. Teramura, H. Tatsumi, H. Asakura, S. Hosokawa, T. Tanaka, Modification of $\mathrm{Ga}_{2} \mathrm{O}_{3}$ by an AgCr core-shell cocatalyst enhances photocatalytic $\mathrm{CO}$ evolution for the conversion of $\mathrm{CO}_{2}$ by $\mathrm{H}_{2} \mathrm{O}$, Chem. Commun. 54 (2018) 1053-1056.

[21] T. Takayama, K. Tanabe, K. Saito, A. Iwase, A. Kudo, The $\mathrm{KCaSrTa}_{5} \mathrm{O}_{15}$ photocatalyst with tungsten bronze structure for water splitting and $\mathrm{CO}_{2}$ reduction, Phys. Chem. Chem. Phys. 16 (2014) 24417-24422.

[22] Z. Wang, K. Teramura, S. Hosokawa, T. Tanaka, Photocatalytic conversion of $\mathrm{CO}_{2}$ in water over Ag-modified $\mathrm{La}_{2} \mathrm{Ti}_{2} \mathrm{O}_{7}$, Appl. Catal. B Environ. 163 (2015) 241-247.

[23] H. Yoshida, L. Zhang, M. Sato, T. Morikawa, T. Kajino, T. Sekito, S. Matsumoto, H. Hirata, Calcium titanate photocatalyst prepared by a flux method for reduction of carbon dioxide with water, Catal. Today. 251 (2015) 132-139.

[24] A. Anzai, N. Fukuo, A. Yamamoto, H. Yoshida, Highly selective photocatalytic reduction of carbon dioxide with water over silver-loaded calcium titanate, Catal. Commun. 100 (2017) 134-138.

[25] S. Xie, Y. Wang, Q. Zhang, W. Deng, Y. Wang, $\mathrm{SrNb}_{2} \mathrm{O}_{6}$ nanoplates as efficient photocatalysts for the preferential reduction of $\mathrm{CO}_{2}$ in the presence of $\mathrm{H}_{2} \mathrm{O}$, Chem. Commun. 51 (2015) 3430-3433.

[26] R. Pang, K. Teramura, H. Asakura, S. Hosokawa, T. Tanaka, Highly selective photocatalytic conversion of $\mathrm{CO}_{2}$ by water over Ag-loaded $\mathrm{SrNb}_{2} \mathrm{O}_{6}$ nanorods, Appl. Catal. B Environ. 218 (2017) 770-778.

[27] H. Yoshida, M. Sato, N. Fukuo, L. Zhang, T. Yoshida, Y. Yamamoto, T. Morikawa, T. Kajino, M. Sakano, T. Sekito, S. Matsumoto, H. Hirata, Sodium hexatitanate photocatalysts prepared by a flux method for reduction of carbon dioxide with water, Catal. Today. 303 (2018) 296-304.

[28] Y.F. Li, Z.P. Liu, L. Liu, W. Gao, Mechanism and activity of photocatalytic oxygen evolution on titania anatase in aqueous surroundings, J. Am. Chem. Soc. 132 (2010) 13008-13015.

[29] A. Vojvodic, J.K. Norskov, Chemistry: Optimizing perovskites for the water-splitting reaction, Science. 334 (2011) 1355-1356.

[30] Z. Fang, D.A. Dixon, Computational study of $\mathrm{H}_{2}$ and $\mathrm{O}_{2}$ production from water splitting by small $\left(\mathrm{MO}_{2}\right)_{\mathrm{n}}$ clusters (M = Ti, Zr, Hf), J. Phys. Chem. A. 117 (2013) 3539-3555.

[31] R. Abe, Recent progress on photocatalytic and photoelectrochemical water splitting under visible light irradiation, J. Photochem. Photobiol. C Photochem. Rev. 11 (2010) 179-209.

[32] T. Berger, M. Sterrer, O. Diwald, E. Knozinger, Charge trapping and photoadsorption of $\mathrm{O}_{2}$ on dehydroxylated $\mathrm{TiO}_{2}$ nanocrystals-An electron paramagnetic resonance study, ChemPhysChem. 6 (2005) 2104-2112.

[33] R.I. Bickley, F.S. Stone, Photoadsorption and photocatalysis at rutile surfaces: I. Photoadsorption of oxygen, J. Catal. 31 (1973) 389-397.

[34] A. Izgorodin, E. Izgorodina, D.R. MacFarlane, Low overpotential water oxidation to hydrogen peroxide on a $\mathrm{MnO}_{\mathrm{x}}$ catalyst, Energy Environ. Sci. 5 (2012) 9496-9501.

[35] O.C. Compton, F.E. Osterloh, Niobate nanosheets as catalysts for photochemical water splitting into 
hydrogen and hydrogen peroxide, J. Phys. Chem. C. 113 (2009) 479-485.

[36] M. Krivec, R. Dillert, D.W. Bahnemann, A. Mehle, J. Strancar, G. Drazic, The nature of chlorine-inhibition of photocatalytic degradation of dichloroacetic acid in a $\mathrm{TiO}_{2}$-based microreactor, Phys. Chem. Chem. Phys. 16 (2014) 14867-14873.

[37] P. Calza, E. Pelizzetti, Photocatalytic transformation of organic compounds in the presence of inorganic ions, Pure Appl. Chem. 73 (2001) 1839-1848.

[38] L. Huang, R. Li, R. Chong, G. Liu, J. Han, C. Li, $\mathrm{Cl}^{-}$making overall water splitting possible on $\mathrm{TiO}_{2}$-based photocatalysts, Catal. Sci. Technol. 4 (2014) 2913-2918.

[39] S. Iguchi, K. Teramura, S. Hosokawa, T. Tanaka, Effect of the chloride ion as a hole scavenger on the photocatalytic conversion of $\mathrm{CO}_{2}$ in an aqueous solution over $\mathrm{Ni}-\mathrm{Al}$ layered double hydroxides, Phys. Chem. Chem. Phys. 17 (2015) 17995-18003.

[40] A.A. Araújo-Filho, F.L.R. Silva, A. Righi, M.B. da Silva, B.P. Silva, E.W.S. Caetano, V.N. Freire, Structural, electronic and optical properties of monoclinic $\mathrm{Na}_{2} \mathrm{Ti}_{3} \mathrm{O}_{7}$ from density functional theory calculations: A comparison with XRD and optical absorption measurements, J. Solid State Chem. 250 (2017) 68-74.

[41] H. Izawa, S. Kikkawa, and M. Koizumi, Ion exchange and dehydration of layered [sodium and potassium] titanates, $\mathrm{Na}_{2} \mathrm{Ti}_{3} \mathrm{O}_{7}$ and $\mathrm{K}_{2} \mathrm{Ti}_{4} \mathrm{O}_{9}, 1129$ (1982) 5023-5026.

[42] E.A. Davis, N.F. Mott, Conduction in non-crystalline systems V. Conductivity, optical absorption and photoconductivity in amorphous semiconductors, Philos. Mag. 22 (1970) 903-922.

[43] K. Carlsson, L. Moberg, B.O. Karlberg, The miniaturisation of the standard method based on the N, N'-Diethyl-PPhenylenediamine (DPD) reagent for the determination of free or combined chlorine, Water research. 33 (1999) 375-380.

[44] L. Moberg, B. Karlberg, An improved $N, N$-diethyl-p-phenylenediamine (DPD) method for the determination of free chlorine based on multiple wavelength detection, Anal. Chim. Acta. 407 (2000) 127-133.

[45] S. Andersson, A.D. Wadsley, The crystal structure of $\mathrm{Na}_{2} \mathrm{Ti}_{3} \mathrm{O}_{7}$, Acta Crystallogr. 14 (1961) 1245-1249.

[46] S. Andersson, A.D. Wadsley, The structures of $\mathrm{Na}_{2} \mathrm{Ti}_{6} \mathrm{O}_{13}$ and $\mathrm{Rb}_{2} \mathrm{Ti}_{6} \mathrm{O}_{13}$ and the alkali metal titanates, Acta Crystallogr. 15 (1962) 194-201.

[47] L.R. Murphy, T.L. Meek, A.L. Allred, L.C. Allen, Evaluation and test of pauling's electronegativity scale, (2000) 5867-5871.

[48] Z. Huang, S. Yoshizawa, K. Teramura, H. Asakura, S. Hosokawa, T. Tanaka, Sodium cation substitution in $\mathrm{Sr}_{2} \mathrm{KTa}_{5} \mathrm{O}_{15}$ toward enhancement of photocatalytic conversion of $\mathrm{CO}_{2}$ using $\mathrm{H}_{2} \mathrm{O}$ as an electron donor, ACS Omega. 2 (2017) 8187-8197.

[49] E. Liu, L. Kang, F. Wu, T. Sun, X. Hu, Y. Yang, H. Liu, J. Fan, Photocatalytic Reduction of $\mathrm{CO}_{2}$ into Methanol over Ag/ $/ \mathrm{TiO}_{2}$ nanocomposites enhanced by surface plasmon resonance, Plasmonics. 9 (2014) 6170.

[50] K. Shao, Y. Wang, M. Iqbal, L. Lin, K. Wang, X. Zhang, M. He, T. He, Modification of Ag nanoparticles on the surface of $\mathrm{SrTiO}_{3}$ particles and resultant influence on photoreduction of $\mathrm{CO}_{2}$, Appl. Surf. Sci. 434 (2018) 717-724.

[51] K. Maeda, D. An, C.S. Kumara Ranasinghe, T. Uchiyama, R. Kuriki, T. Kanazawa, D. Lu, S. Nozawa, A. Yamakata, Y. Uchimoto, O. Ishitani, Visible-light $\mathrm{CO}_{2}$ reduction over a ruthenium(II)-complex $/ \mathrm{C}_{3} \mathrm{~N}_{4}$ hybrid photocatalyst: The promotional effect of silver species, J. Mater. Chem. A. 6 (2018) 9708-9715.

[52] Y. Kawaguchi, M. Akatsuka, M. Yamamoto, K. Yoshioka, A. Ozawa, Y. Kato, T. Yoshida, Preparation of gallium oxide photocatalysts and their silver loading effects on the carbon dioxide reduction with water, J. Photochem. Photobiol. A Chem. 358 (2018) 459-464.

[53] Z. Wang, K. Teramura, S. Hosokawa, T. Tanaka, Highly efficient photocatalytic conversion of $\mathrm{CO}_{2}$ into solid $\mathrm{CO}$ using $\mathrm{H}_{2} \mathrm{O}$ as a reductant over Ag-modified $\mathrm{ZnGa}_{2} \mathrm{O}_{4}$, J. Mater. Chem. A. 3 (2015) 11313-11319.

[54] A. Harriman, I.J. Pickering, J.M. Thomas, P.A. Christensen, Metal oxides as heterogeneous catalysts for oxygen evolution under photochemical conditions, J . Chem. SOC. Furuduy Trans. I. 84 (1988) 2795-2806.

[55] R.K. Hocking, R. Brimblecombe, L.Y. Chang, A. Singh, M.H. Cheah, C. Glover, W.H. Casey, L. Spiccia, Water-oxidation catalysis by manganese in a geochemical-like cycle, Nat. Chem. 3 (2011) 461-466.

[56] F. Jiao, H. Frei, Nanostructured manganese oxide clusters supported on mesoporous silica as efficient oxygenevolving catalysts, Chem. Commun. 46 (2010) 2920-2922.

[57] D. Marxer, P. Furler, M. Takacs, A. Steinfeld, Solar thermochemical splitting of $\mathrm{CO}_{2}$ into separate streams of $\mathrm{CO}$ and $\mathrm{O}_{2}$ with high selectivity, stability, conversion, and efficiency, Energy Environ. Sci. 10 (2017) 1142-1149.

[58] L. Huang, J. Jiang, L. Ai, Interlayer Expansion of Layered Cobalt Hydroxide nanobelts to highly improve oxygen evolution electrocatalysis, ACS Appl. Mater. Interfaces. 9 (2017) 7059-7067.

[59] Z. Luo, C. Li, S. Liu, T. Wang, J. Gong, Gradient doping of phosphorus in $\mathrm{Fe}_{2} \mathrm{O}_{3}$ nanoarray photoanodes for enhanced charge separation, Chem. Sci. 8 (2017) 91-100. 
[60] A. Kudo, Y. Miseki, Heterogeneous photocatalyst materials for water splitting, Chem. Soc. Rev. 38 (2009) 253-278.

[61] H. Muraki, T. Saji, M. Fujihira, S. Aoyagui, Photocatalytic oxidation of water to hydrogen peroxide by irradiation of aqueous suspensions of $\mathrm{TiO}_{2}$, J. Electroanal. Chem. Interfacial Electrochem. 169 (1984) 319323. 